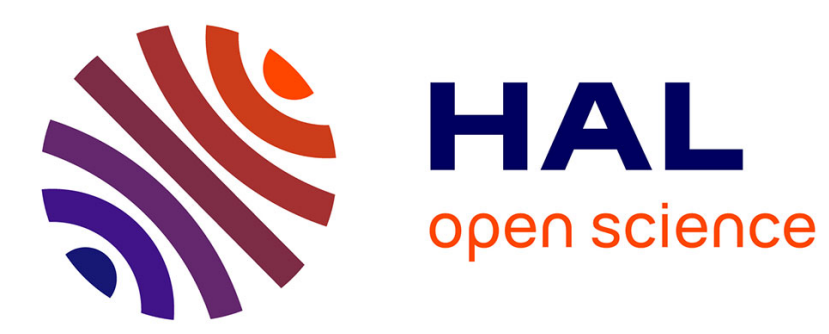

\title{
HARDENING MECHANISMS OF IONIC CRYSTALS ON 110 AND 100 SLIP PLANES
}

\author{
W. Skrotzki, P. Haasen
}

\section{To cite this version:}

W. Skrotzki, P. Haasen. HARDENING MECHANISMS OF IONIC CRYSTALS ON 110 AND 100 SLIP PLANES. Journal de Physique Colloques, 1981, 42 (C3), pp.C3-119-C3-148. 10.1051/jphyscol:1981312 . jpa-00220703

\section{HAL Id: jpa-00220703 https://hal.science/jpa-00220703}

Submitted on 1 Jan 1981

HAL is a multi-disciplinary open access archive for the deposit and dissemination of scientific research documents, whether they are published or not. The documents may come from teaching and research institutions in France or abroad, or from public or private research centers.
L'archive ouverte pluridisciplinaire HAL, est destinée au dépôt et à la diffusion de documents scientifiques de niveau recherche, publiés ou non, émanant des établissements d'enseignement et de recherche français ou étrangers, des laboratoires publics ou privés. 


\title{
HARDENING MECHANISMS OF IONIC CRYSTALS ON $\{110\}$ AND $\{100\}$ SLIP PLANES
}

\author{
W. Skrotzki and P. Haasen \\ Institut für Metalzphysik, Universität, Göttingen, REA.
}

\begin{abstract}
Résumé. - Les cristaux ioniques de la structure NaCl peuvent être déformés sur plusieurs plans cristallographiquement non-équivalents. La résistance à la déformation varie avec le type du système de glissement. Cette anisotropie plastique dépend de la température, du dopage bivalent et de l'ionicité du matériau. C'est dêmontré par des mesures de la limite élastique pour le glissement sur les plans $\{110\}$ et $\{100\}$. Pour une série de cristaux du type NaCl les mécanismes de durcissement qui sont basés sur les interactions de Peierls et dislocation-solute sont discutés. L'anisotropie plastique est une aide substantielle pour 1 'analyse de ces interactions.
\end{abstract}

\begin{abstract}
Ionic crystals of the NaCl structure can be deformed on several nonequivalent crystallographic planes. The hardness varies with the type of slip system. This plastic anisotropy depends on temperature, divalent doping and ionicity of the material as is shown by measurements of the critical resolved shear stress for slip on $\{110\}$ and $\{100\}$ planes. For a series of NaC1-type crystals hardening mechanisms are discussed based on Peierls and dislocationsolute interactions. The plastic anisotropy is of substantial help in the analysis of these interactions.
\end{abstract}

1. Introduction. - The hardening of ionic crystals has been frequently investigated. Nevertheless, the interaction mechanisms determining the critical resolved shear stress (CRSS) of these materials are still under dispute. Suzuki and $\mathrm{Kim} / 1,2 /$ in agreement with calculations of Granzer et al. $/ 3 /$ conclude from their measurements of the CRSS of relatively pure crystals, that at low temperatures the overcoming of the Peierls potential is responsible for the CRSS. Frank /4/ as well as Suszynska /5/ and Grau and Fröhlich /6/ assume that in doped crystals at medium temperatures the elastic interaction of screw dislocations with divalent ion vacancy dipoles or aggregates of such dipoles determines yielding. These investigations are, however, limited to $\{110\}\langle 110\rangle$ glide. $\{100\}\langle 110>$ slip could be realized as well in previous work $/ 7 /$. It showed that for the understanding of the plastic anisotropy electrostatic interactions have to be taken into account.

The purpose of the present paper is to present detailed information on slip mechanisms in ionic crystals from extended measurements of the dependence of the CRSS on temperature, divalent doping, slip system and ionicity of several materials. Especially the plastic anisotropy helps to decide whether models based on elastic or electrostatic inter- 
actions are able to describe the onset of the plastic deformation.

2. Experimental. - The experiments were carried out on alkali and silver halide single crystals grown by the Kyropoulos method. For the growth of silver chloride crystals NaCl seed crystals were used /8/. Starting material, dopants and growth parameters are listed in table $I$.

Table I.- Crystal growth parameters

\begin{tabular}{|c|c|c|c|c|}
\hline & Starting material (origin) & Atmosphere & Crucible & Dopant \\
\hline $\mathrm{NaCl}$ & suprapur (Merck, FRG) & Air & Porcelain & $\mathrm{SrCl}_{2}$ \\
\hline $\mathrm{KCl}$ & pro analysi (Merck) & Air & Porcelain & $\mathrm{SrCl}_{2}$ \\
\hline $\mathrm{KBr}$ & pro analysi (Riedel de Häen,FRG) & Air & Porcelain & $\mathrm{SrBr}_{2}$ \\
\hline $\mathrm{KJ}$ & suprapur (Merck) & Argon & Platinum & $\mathrm{SrJ}_{2}$ \\
\hline $\mathrm{AgCl}$ & optipur (Merck) & Argon & Quartz & $\mathrm{CaCl}_{2}$ \\
\hline
\end{tabular}

Purity was determined by atomic absorption analysis. <100>- orientated specimens with $\{100\}-s i d e$ faces could be obtained by cleavage, while $<111>-o r<557>$-orientated specimens with $\{110\}-$ and $\{112\}-$ or $\{110\}-$ and $\{7,7,10\}$ - side faces, respectively, had to be string sawn with water. In the case of the AgCl crystal all specimens had to be sawn using a fixing reagent in dark room red light. The orientation of the AgCl samples could be easily found with the aid of the <100>-orientated NaCl seed crystal. The accuracy amounted to 3 degrees. Specimen dimensions were about $4 \times 4 \times 18 \mathrm{~mm}^{3}$. Before testing all samples were annealed on a platinum foil for $20 \mathrm{~h}$ at $\sim 0.85 \mathrm{~T}_{\mathrm{m}}\left(\mathrm{T}_{\mathrm{m}}=\right.$ melting temperature). Annealing and growth atmosphere were identical. The standard cooling rate was about. $1 \mathrm{~K} / \mathrm{min}$. (SC), while for some specimens quenched from $700 \mathrm{~K}$ it was about hundred times higher $(Q)$. All samples have been polished first mechanically on wetted silk and then chemically in different solutions. Suitable etchants to reveal dislocations were found. Details of the polishing and etching procedures are given in $/ 9 /$.

The deformation was performed in dynamic compression using an Instron-machine. The average strain rate was about $\dot{\varepsilon} \approx 10^{-4} \mathrm{~s}^{-1}$. Room temperature deformation was performed in air. For lower and higher temperatures suitable compression devices were immersed in baths of liquid helium, liquid nitrogen, isopentane and silicon oil. The AgCl crystals were deformed in darkroom red light. 


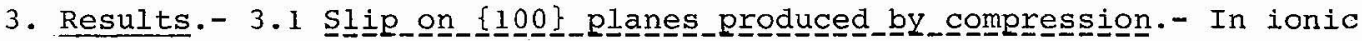
crystals single slip on $\{110\}$ or $\{100\}$ planes has previously been achieved in shear tests /7/. This deformation method has however the disadvantage that it can be used only at room temperature (RT). Therefore we have realized it by compression of suitably orientated crystals. In this section it will be shown that large scale macroscopic slip on $\{100\}$ planes alone could be realized over a wide range of temperature.

Assuming Schmid's law in crystals of any orientation a slip system with the. CRSS $\tau_{C}$ will be activated first if the condition $\tau_{C}<\tau_{C i}$. $S_{1} / S_{i}$ is fullfilled $\left(S_{1}=\right.$ Schmid factor of the first system, $S_{i}$, ${ }_{c i}$ those of the other systems). Thus slip on a $\{110\}$ or a $\{100\}$ plane alone is to be expected only for orientations adjacent to $\langle 100\rangle$ and $\langle 111\rangle$, respectively.

Deforming crystals in $<100>$-orientation $\left(S_{\max }(\{110\}<110>)=0.5\right.$, $\left.S_{\max }(\{100\}\langle 110\rangle)=0\right)$ slip usually starts on more than one $\left.\{110\}<110\right\rangle$ system (Fig. 1).

[001]
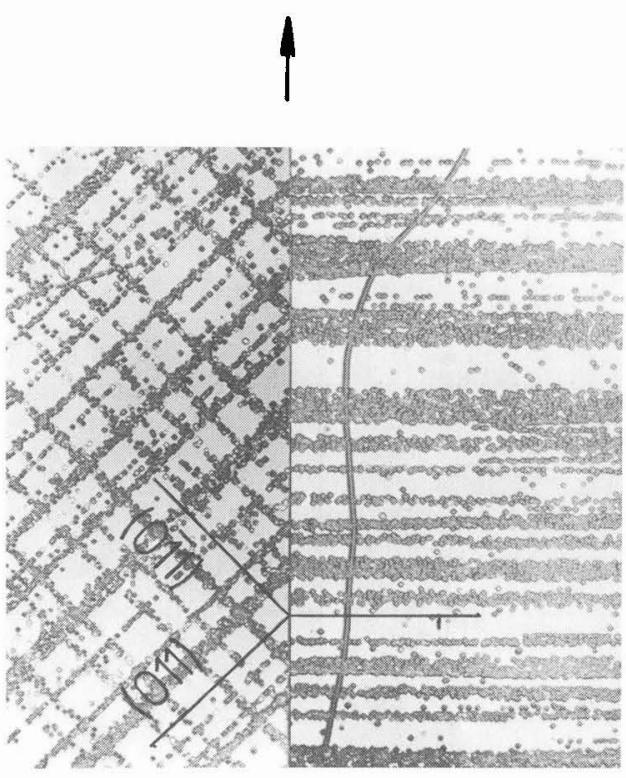

(100)

\section{$\mathrm{KCl}$}

[55̄7]
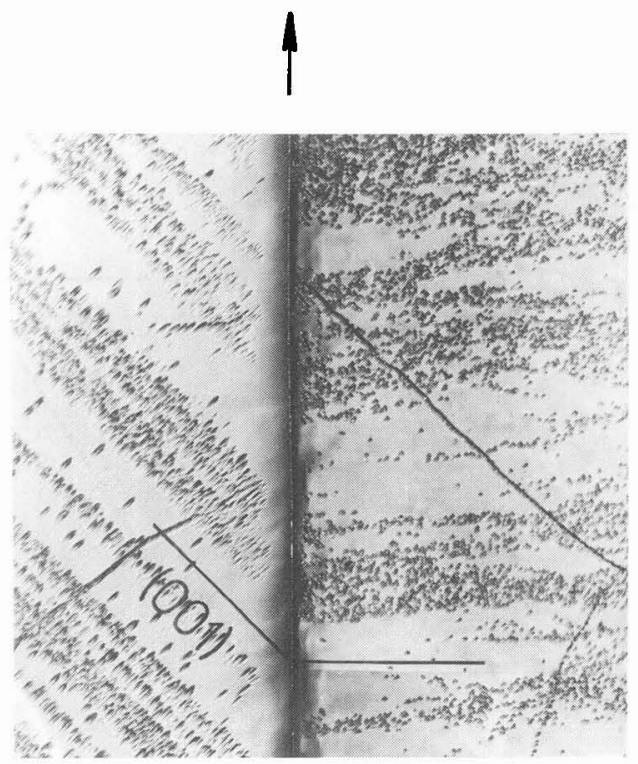

(110)

(7770)

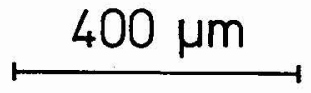

Fig. 1 - Etched surfaces of square KCI crystals $\left(c_{\mathrm{Sr}^{2}+}=56 \mathrm{ppm}\right)$ deformed along [001] and [557] in compression at RT. 
Using $\langle 557\rangle\left(\hat{\equiv}\langle 111\rangle+10^{\circ}\right)$-orientated crystals $\left(\mathrm{S}_{\max }(\{110\}<110\rangle\right)=$ $\left.0.12, \mathrm{~S}_{\max }(\{100\}<110>)=0.5\right)$ deformation begins on a single $\{100\}$ plane (Fig. 1). Particularly interesting is the difference in the slip bands produced by the screw dislocations (Fig. 1 : side faces (010) and $(7,7,10))$. Changing to the $\langle 111\rangle$-orientation $\left(S_{\max }(\{110\}<110>)=0\right.$, $\left.\left.\mathrm{S}_{\max }(\{100\}<110\rangle\right)=0.47\right)$ three $\left.\{100\}<110\right\rangle$ systems are equally stressed. Hence, slip on more than one $\{100\}$ plane has been observed (Fig. 2). This is demonstrated by the etch pit traces on the ( $\overline{1} 12$ ) side face as well as on the (001) cleavage plane. The absence of traces on the (001) plane perpendicular to [līo] means that traces on ( 112 ) perpendicular to $[1 \overline{1} 1]$ are produced by screw dislocations which have moved on $(001)$. It is emphasized that for all the investigated crystals $\{111\}<110>$ slip has never been observed, contrary to the statements of Bhagavan Raju and strunk /10/.

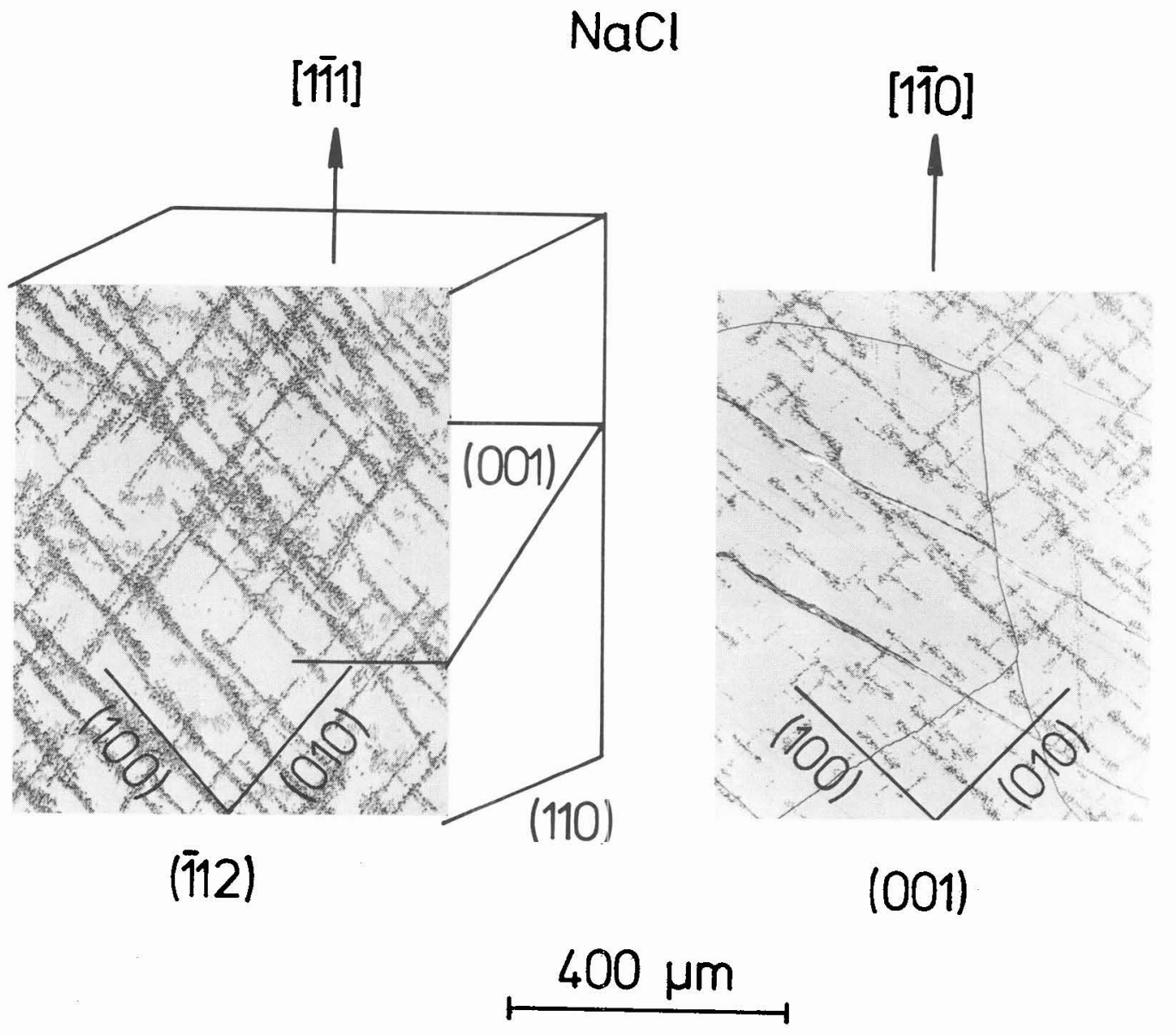

Fig. 2.- Etch pit arrangement on the (1112) side face and the (001) cleavage plane of $\mathrm{NaCl}\left(\mathrm{c}_{\mathrm{Sr}^{2}+}=63 \mathrm{ppm}\right)$ after RT deformation of <ll1> -orientated crystals. 
Because of multiple slip the <ll1> -orientated crystals show strong work-hardening which decreases with increasing doping (Fig.3).

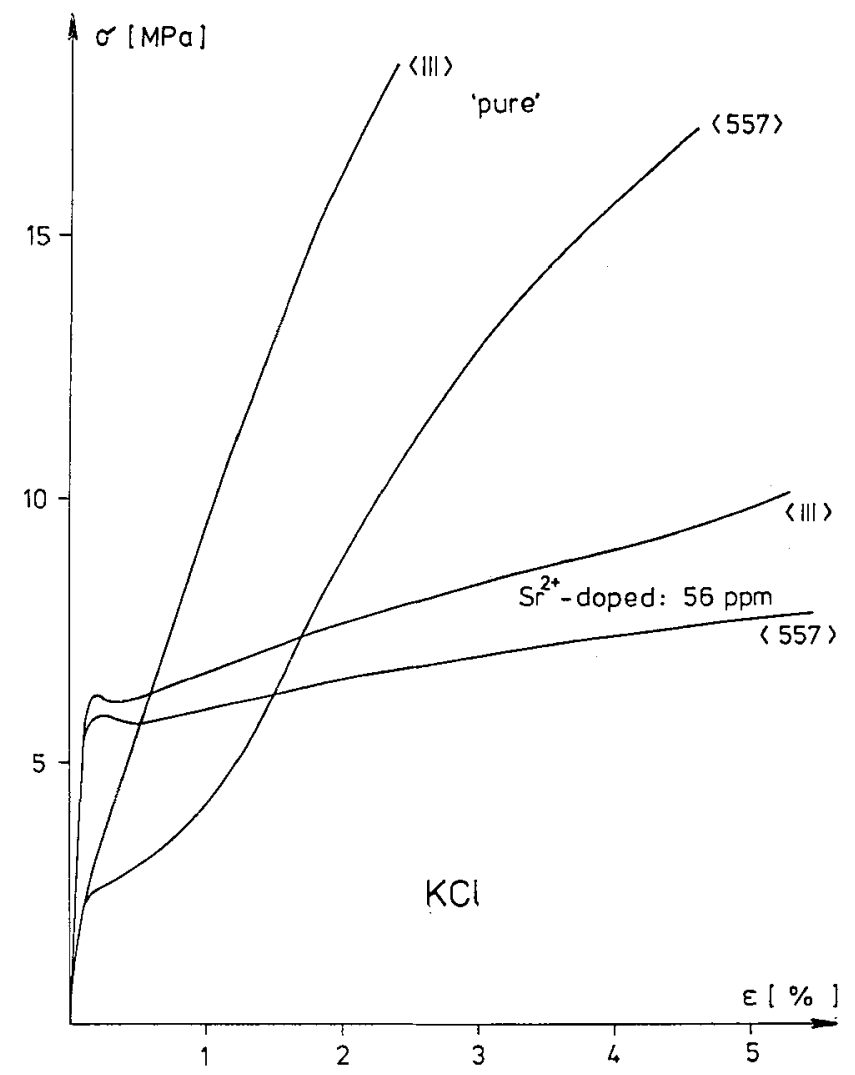

Fig. 3.- RT stress-strain curves of "pure" and $\mathrm{Sr}^{2+}$ doped KCl. crystals compressed in $\langle 111\rangle$ and $\langle 557\rangle$ orientations.

Therefore <557>-orientated crystals are preferred for the determination of the CRSS on $\{100\}$. However, this is only possible as long as the ratio $\tau_{C}\{100\} / \tau_{C}\{110\}$ is smaller than that of the schmid factors (S $\{100\}$ $\left.\mathrm{s}^{\{110\}}=4\right)$.

The movement of edge and screw dislocations in dependence of temperature, doping, slip sytem and ionicity of the material will be described in a separate paper.

3.2. Measurements_of of the_CRSS.- 3.2.1. Determination of the CRSS.- In ionic crystals the onset of the plastic deformation marks itself in different ways in stress strain curves (SSC). A schematical description of typical SSC and of the determination of the CRSS from them is given in figure 4. 


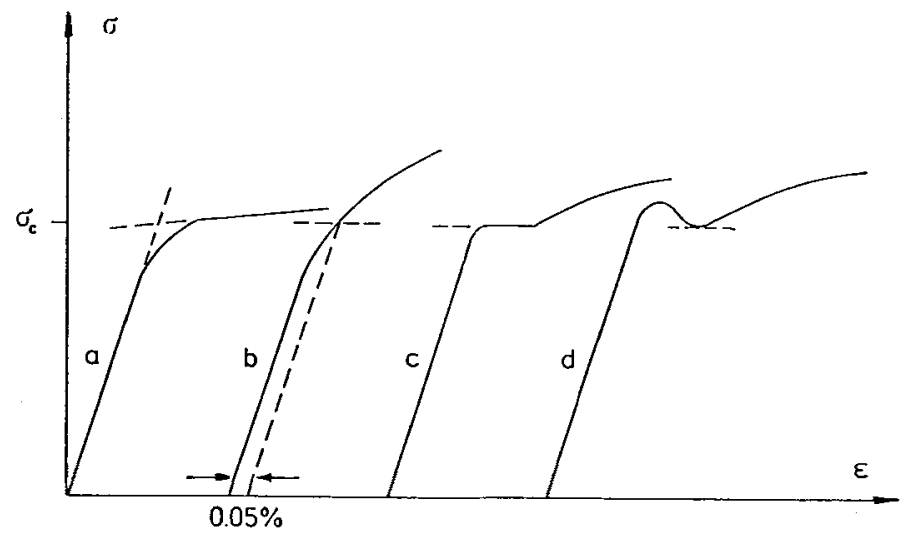

Fig. 4.- Typical initial stages of stress-strain curves and determination of the CRSS.

Most specimens showed SSC of type a). Curves of type b) have been observed for <111>-orientated crystals. Parabolic curves were shown by all orientations at high temperatures, for $<557>-$ and $<111>-o r i e n t a t i o n s$ also at low temperatures. Curves of type c) and $d$ ) have only been observed for doped crystals. The maximum scatter of the CRSS of identical specimens was $5 \%$.

3.2.2 Dependence of the CRSS on temperature and doping.- In ionic crystals a decrease of the CRSS with increasing temperature occurs in several regimes, schematically presented in figure 5. Crystals doped with a certain concentration of divalent impurities show a decrease in four regimes. With increasing purity of the material the temperature dependence of the CRSS approaches that indicated by the dotted line.

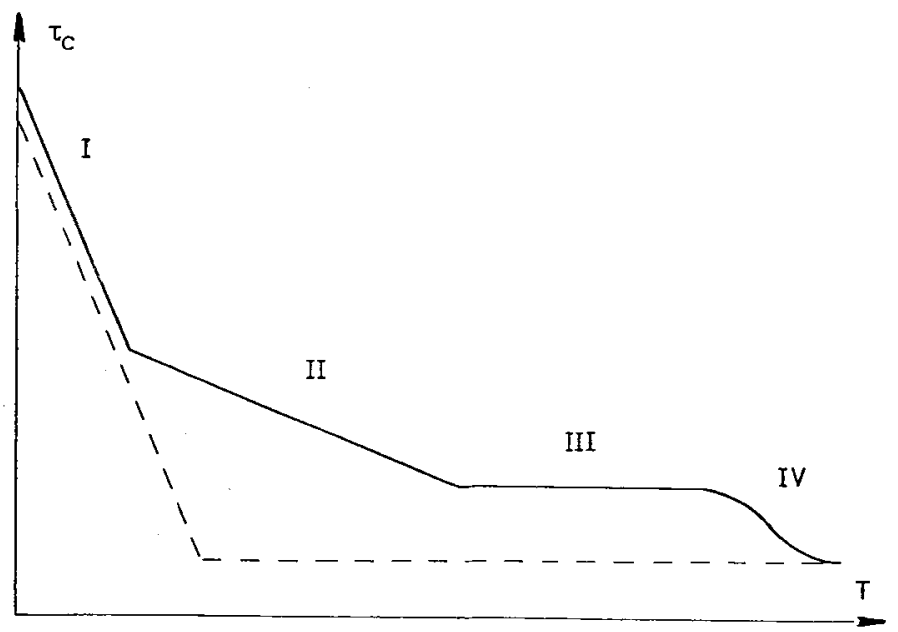

Fig. 5.- Schematic regimes of the temperature dependence of the CRss of ionic crystals. Dotted and traced lines belong to "pure" and doped crystals, respectively. 
In the following these regimes will be characterized in terms of the dependence of the CRSS on temperature, doping, slip system and ionicity of the material.

Regime I.- Details on regime I for $\{100\}$ slip have been presented elsewhere $/ 11 /$. Here further results will be presented which demonstrate the intrinsic plastic anisotropy. Figure 6a shows the temperature dependence of the CRSS for slip on $\{110\}$ and $\{100\}$ planes. The values for $\tau_{c}\{100\}$ marked by half-filled symbols have been obtained by extrapolation from $\mathrm{KCl}-\mathrm{KBr}$ solid solutions /11/. Striking is the strong plastic anisotropy below a certain temperature which depends on the material. The usual scaling of different materials in terms of the shear modulus and the melting temperature does not work for ionic crystals (Fig. 6b).

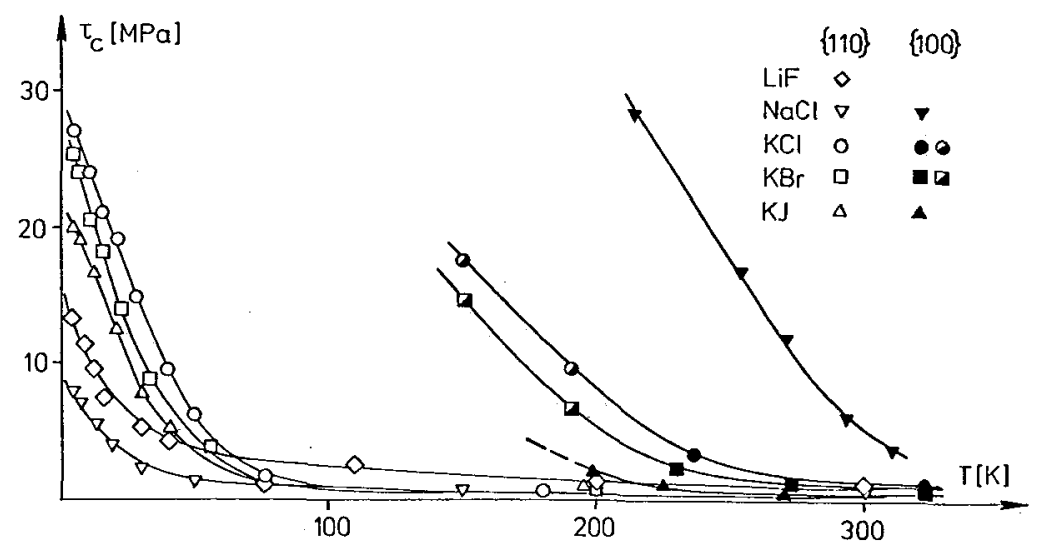

Fig. 6a.- Temperature dependence of the CRSS of "pure" crystals. Half-filled symbols are extrapolated from $\mathrm{KCI}-\mathrm{KBr}$ solid solutions $(\diamond / 1 /, \nabla / 2 /, 0 \Delta \Delta$ by T. Suzuki (to be published), $\nabla / 12 /$ )

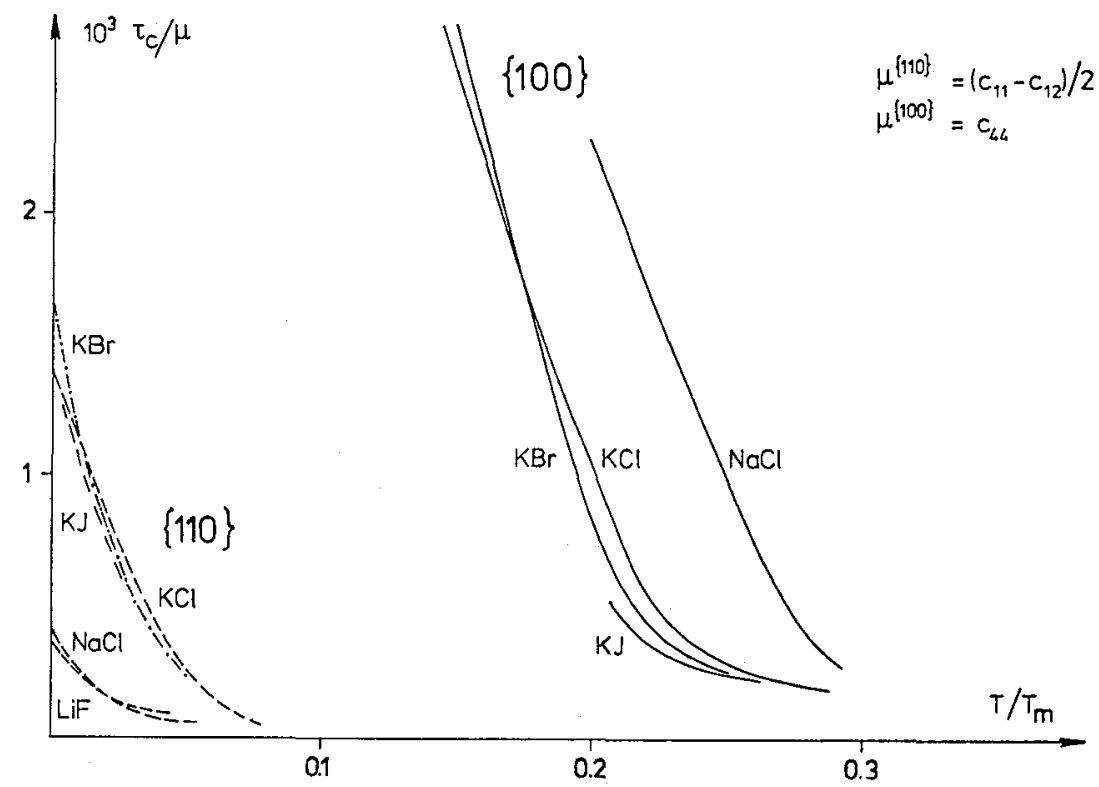

Fig. 6b.- Curves of (a) reduced by the shear modulus $\mu$ and the meltine temberature $T$ 
The dependence of the CRSS on divalent doping is presented in figures 7 and 8 .

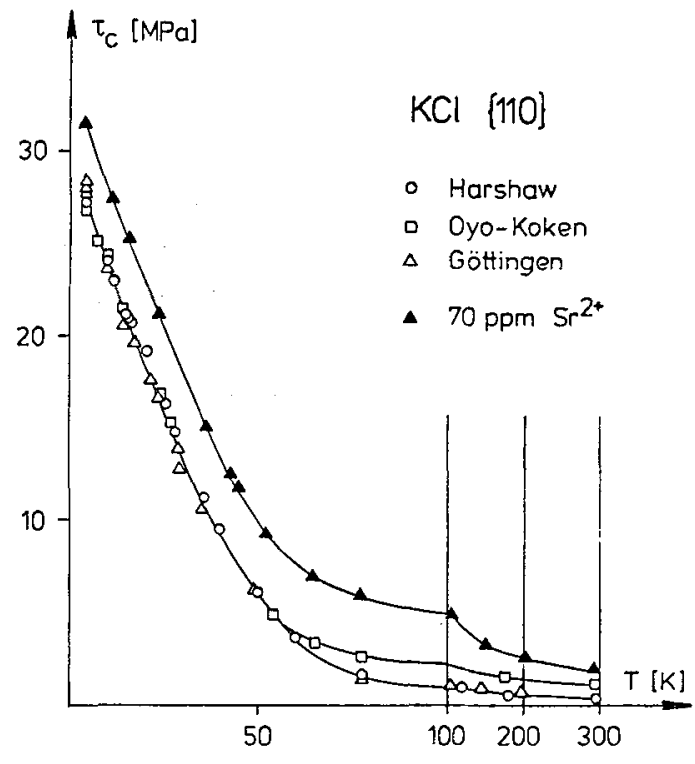

Fig. 7.- Temperature dependence of the CRSS of $\mathrm{KCl}$ for $\{110\}$ slip. Open symbols represent "pure" crystals of different origin.

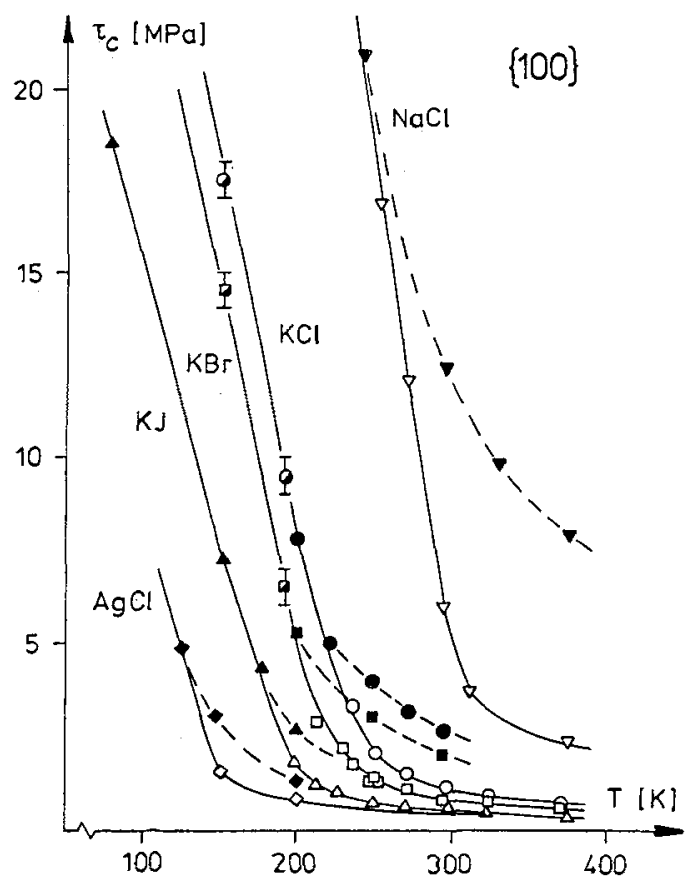

Fig. 8.- Temperature dependence of the CRSS for $\{100\}$ slip. Open and filled symbols

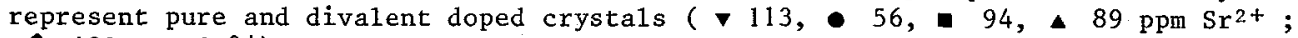
$483 \mathrm{ppm} \mathrm{Ca}^{2+}$ ). 
Doped crystals show the same temperature dependence in regime I as "pure" ones. Moreover, doping has a greater influence on $\{110\}$ than on $\{100\}$ slip. For $\{100\}$ the CRSS of the doped crystals agree with those of the "pure" ones at low temperatures. Remarkable is also the good agreement between the CRSS of "pure" crystals of different origins (Fig.7) . The solution hardening of $\mathrm{KCl} \tau_{\mathrm{C}}\left(70 \mathrm{ppm} \mathrm{Sr}^{2+}\right)$ relative to $\tau_{\mathrm{C}}$ ("pure") for $\{110\} \mathrm{slip}$ amounts to about $10 \%$ at $4.2 \mathrm{~K}$. It is also noted that the activation volume is smaller than $100 \mathrm{~b}^{3}$ in regime $\mathrm{I} / 11 /$.

Regime II.- In figures $9 a-e$ the temperature dependence of the CRSS is presented in such a way that regimes II-IV can be recognized clearly. A comparison of these figures shows a qualitative similarity between all the materials investigated. The temperature dependence of the CRSS is smaller in regime II than in regime $I$, see figure $9 b$. With increasing purity of the material the decrease in $\tau_{C}(T)$ becomes smaller.

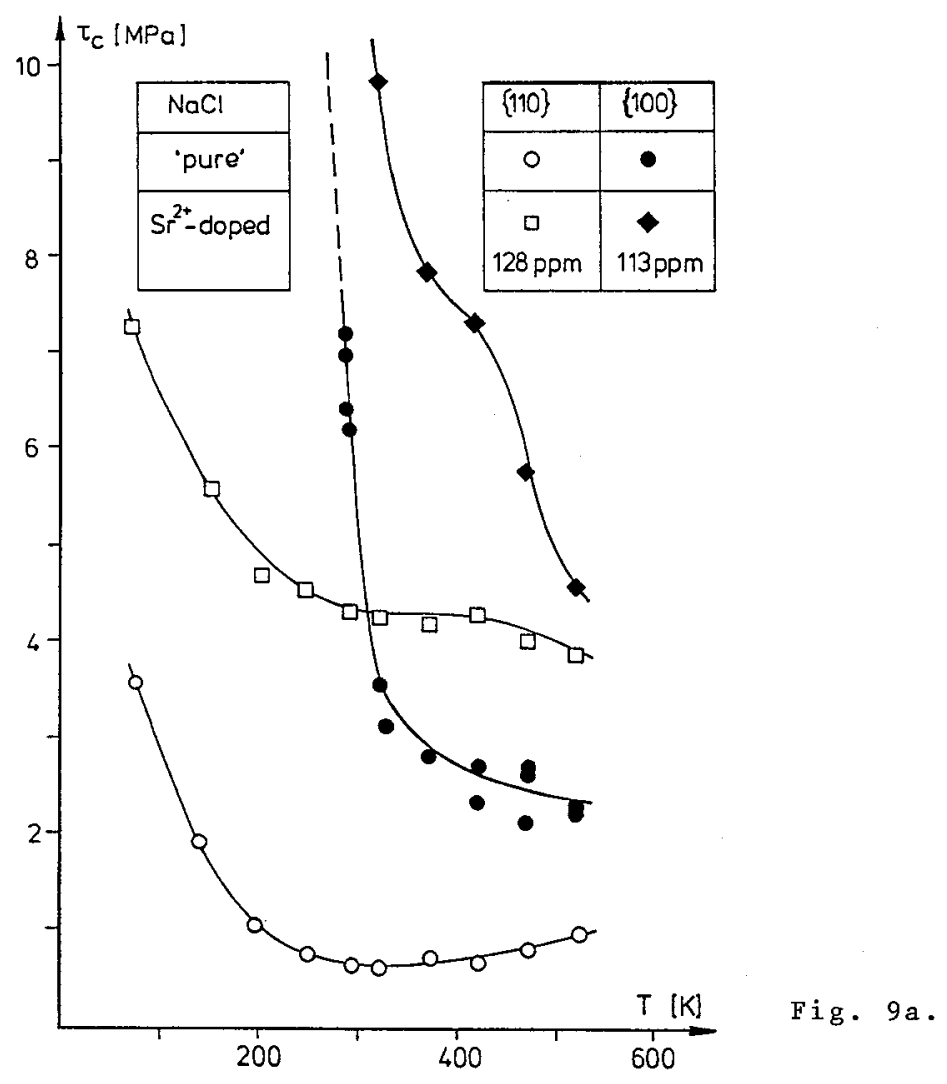




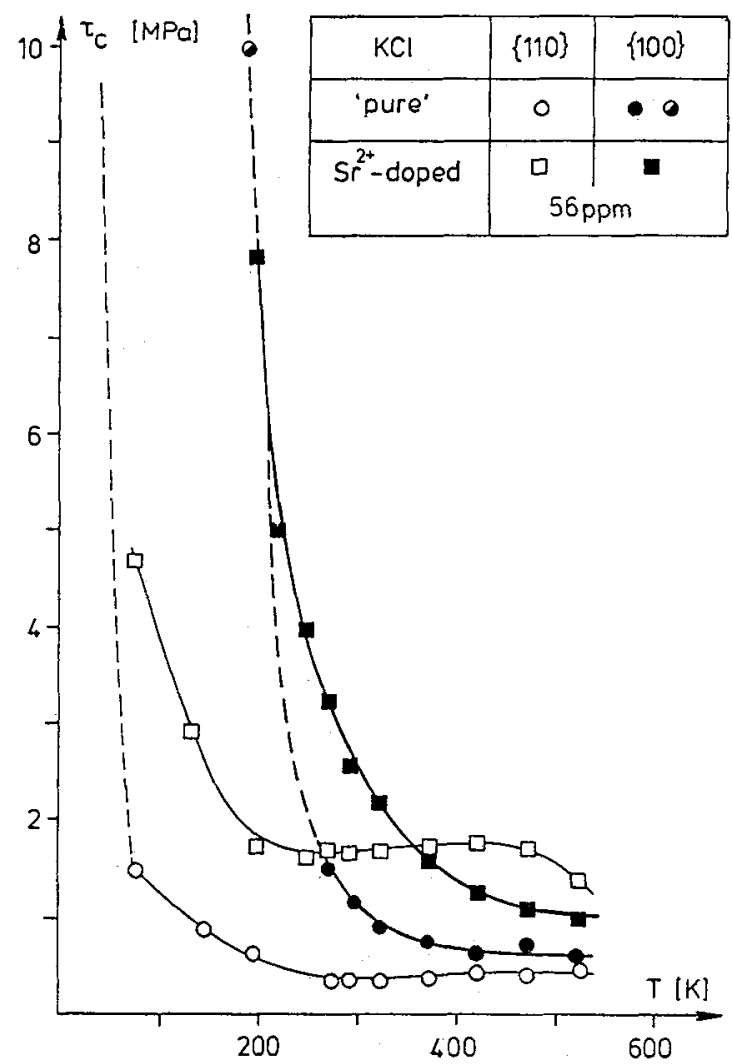

Fig. $9 b$.

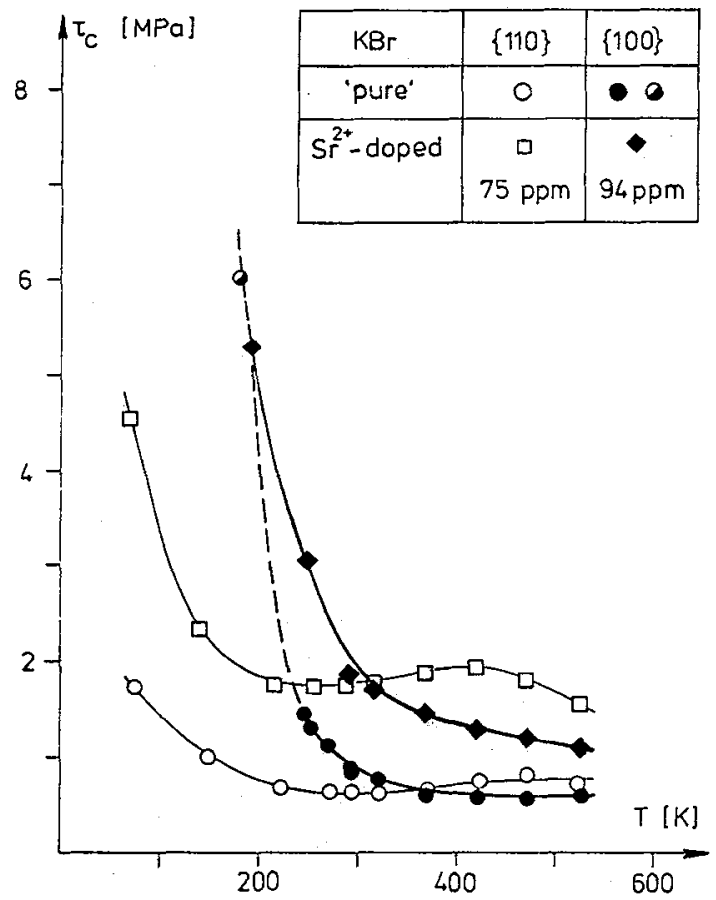

Fig. 9c. 

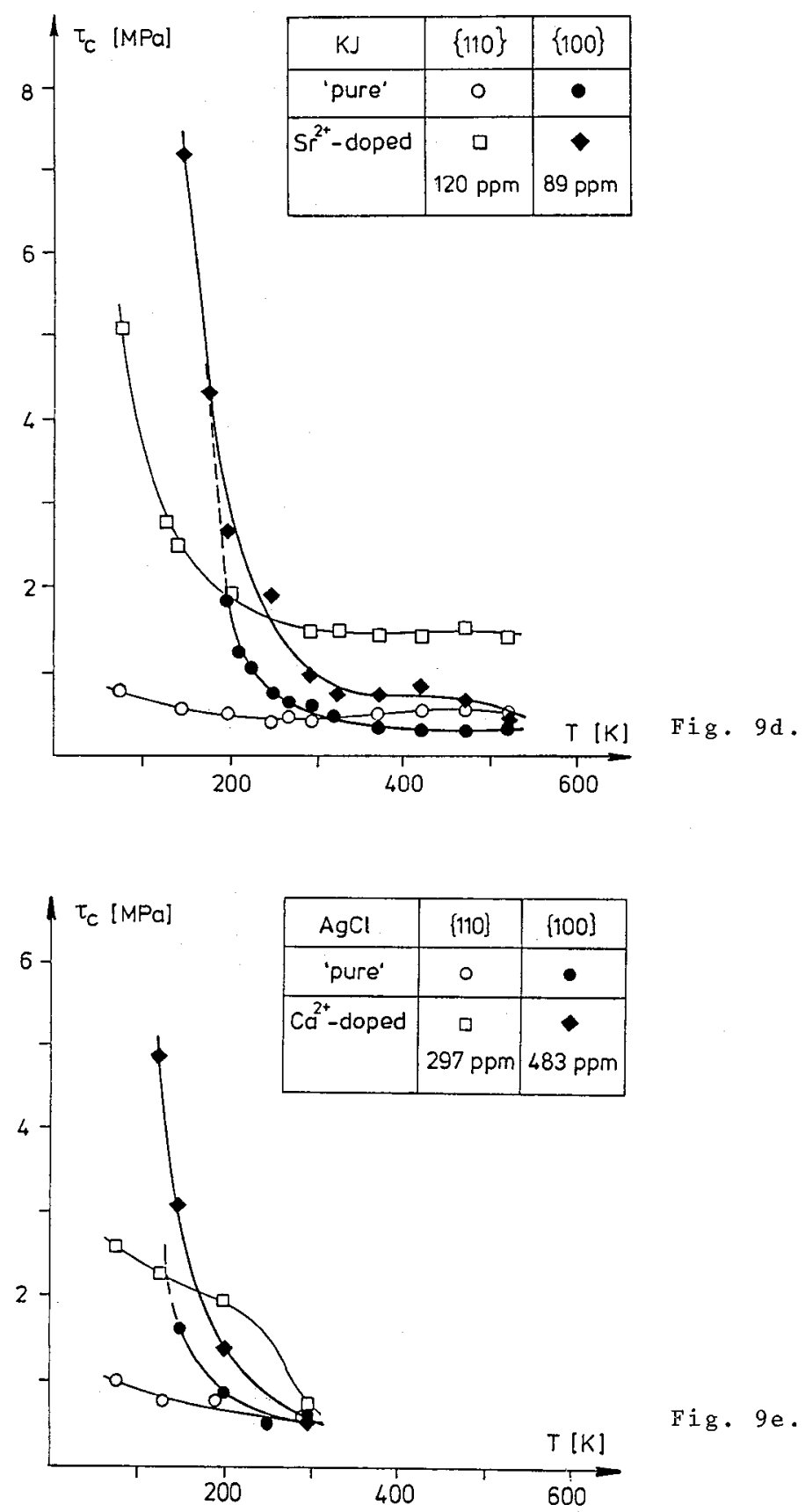

Fig. 9e.

Fig. 9a-e.- Temperature dependence of the CRSS of "pure" and doped crystals for slip on $\{110\}$ and $\{100\}$ planes. 
The concentration dependence of the CRSS shown in figures $10 \mathrm{a}$ and $\mathrm{b}$ is more or less parabolic depending on the material. Values for $\tau_{c}\{100\}$ obtained using cristals of different orientations agree well (Fig. lOb).
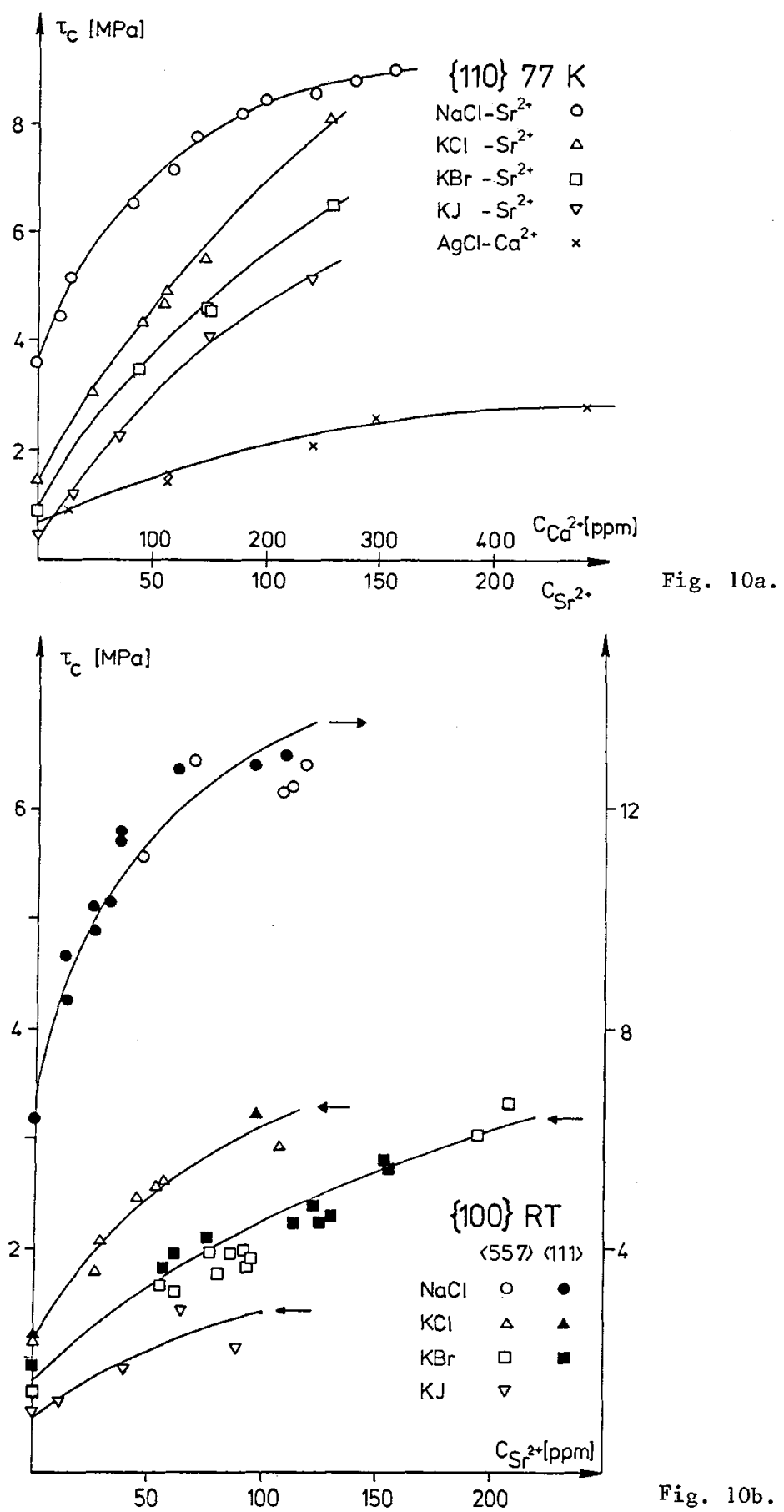

Fig. 10a-b.- Concentration dependence of the CRSS for $\{110\}$ (a) and $\{100\}$ slip (b) in regime II 
Regime III.- Here the CRSS is nearly temperature independent (Figs. 9 a-e). With increasing temperature sometimes a weak increase is observed. Figures $11 \mathrm{a}$ and $\mathrm{b}$ show the dependence of the CRSS on divalent doping. For all materials and concentrations investigated (except $\mathrm{NaCl}-\mathrm{Sr}^{2+}$ ) the CRSS is a linear function of the dopant concentration $\mathrm{Clf}^{2+}$ (for the alkali halides ${ }^{c} \mathrm{Sr}^{2}+\leqslant 150 \mathrm{ppm}$, for. $\mathrm{AgCl} \mathrm{C}_{\mathrm{Ca}^{2}} \leqslant 500 \mathrm{ppm}$. Quenching experiments on $\mathrm{Sr}^{2+}$ doped $\mathrm{NaCl}, \mathrm{KCl}$ and $\mathrm{KBr}$ crystals showed that only the $\mathrm{NaCl}-\mathrm{Sr}^{2+}$ hardening is strongly dependent on the cooling rate (Fig. 12). The CRSS of quenched $\mathrm{NaCl}-\mathrm{Sr}^{2+}$ depends also linearly on the dopant concentration. The quenching effect on the slope of $\tau_{C}\left(c_{\mathrm{Sr}_{2}+}\right)$ for KCl and $\mathrm{KBr}$ is only 14 and $4 \%$, respectively.
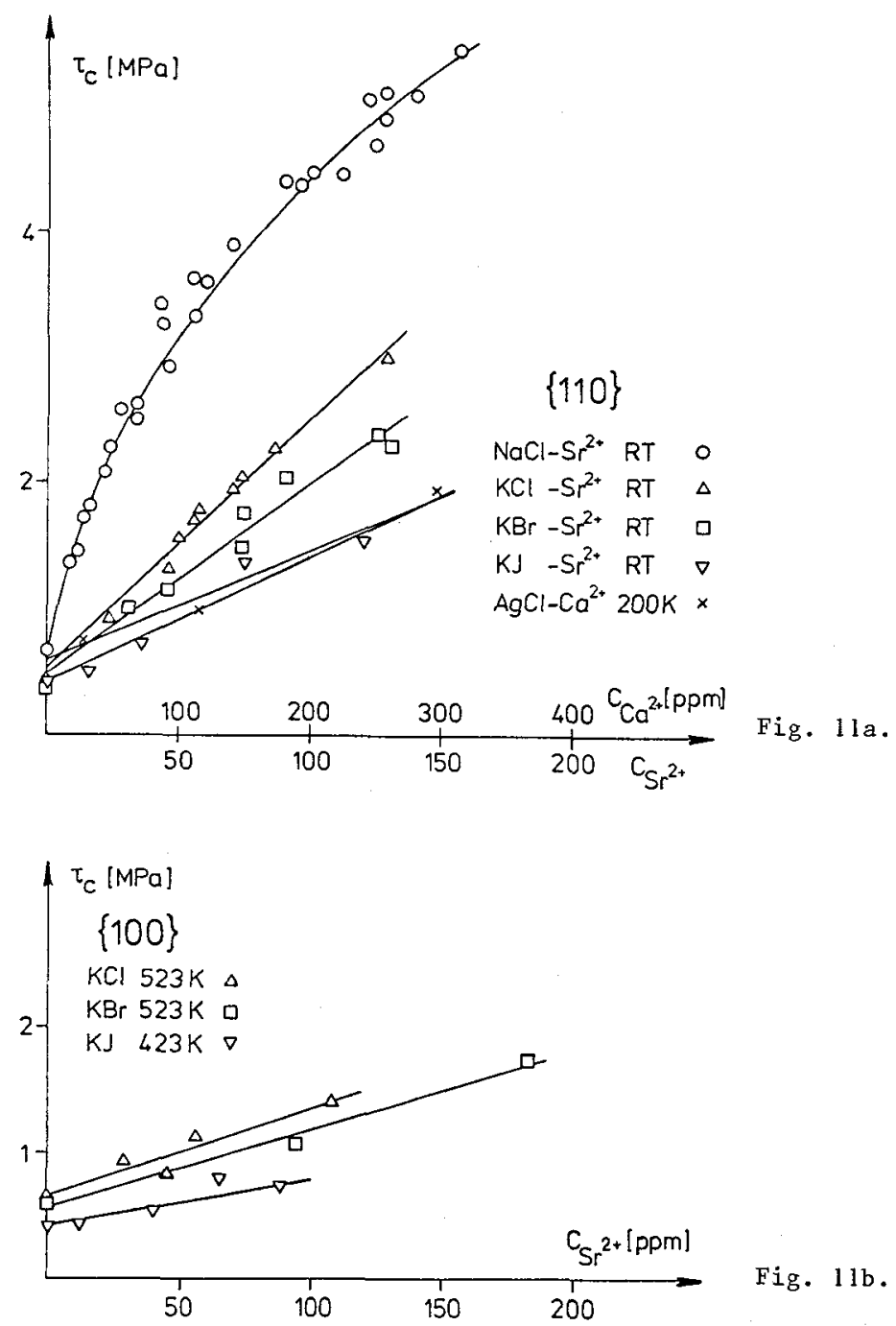

Fig. Ila-b.- As זigure 10 for regime III. 


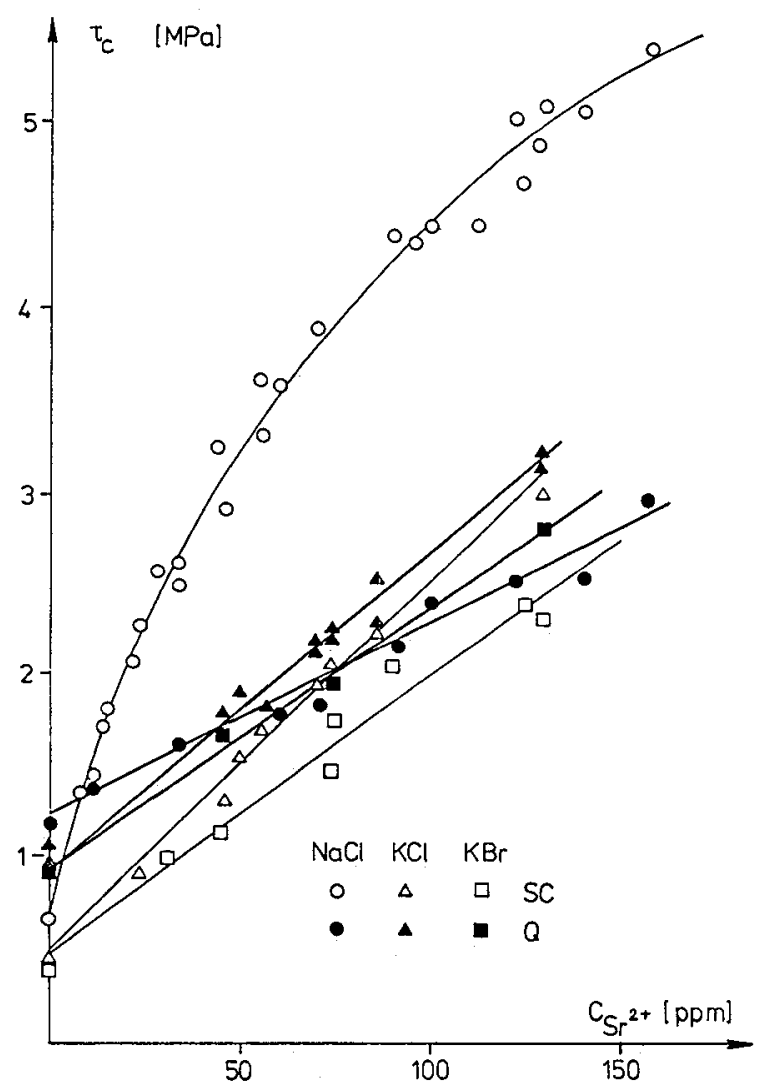

Fig. 12.- Concentration dependence of the CRSS for $\{110\}$ slip at RT after cooling with different rates.

We would like to point out that quenching experiments are more problematic than frequently described. This is already indicated by an increase of the CRSS of "pure" crystals by a factor of two due to quenching. Parallel to that an increase of the dislocation density from $2 \times 10^{4}$ to $2 \times 10^{6} \mathrm{~cm}^{-2}$ is observed. So quenching does not only change the impurity aggregation state but also the dislocation-dislocation interaction. Qualitatively the same results have been obtained under comparable conditions by Suszynska /5/ for $\mathrm{NaCl}-\mathrm{Sr}^{2+}$ while for $\mathrm{KCl}-\mathrm{Sr}{ }^{2+}$ there exists large discrepancy between her results and ours.

The effect of the cooling rate on the temperature dependence of the CRSS is shown for NaCl-Sr ${ }^{2+}$ in figure 13. The CRSS of quenched crystals decreases much more strongly with increasing temperature than that of slowly cooled samples. Below a certain temperature quench-hardening, above quench-softening occurs. Above RT the CRSS for $\{110\}$ slip in quenched crystals is increasing with temperature. In the same tempe- 
rature range a change in slope for $\tau_{\mathrm{C}}\{100\}$ (T) is observed, too. The same behaviour has been described by Johnston/13/ for $\{110\}$ slip in $\mathrm{LiF}-\mathrm{Mg}^{2+}$.

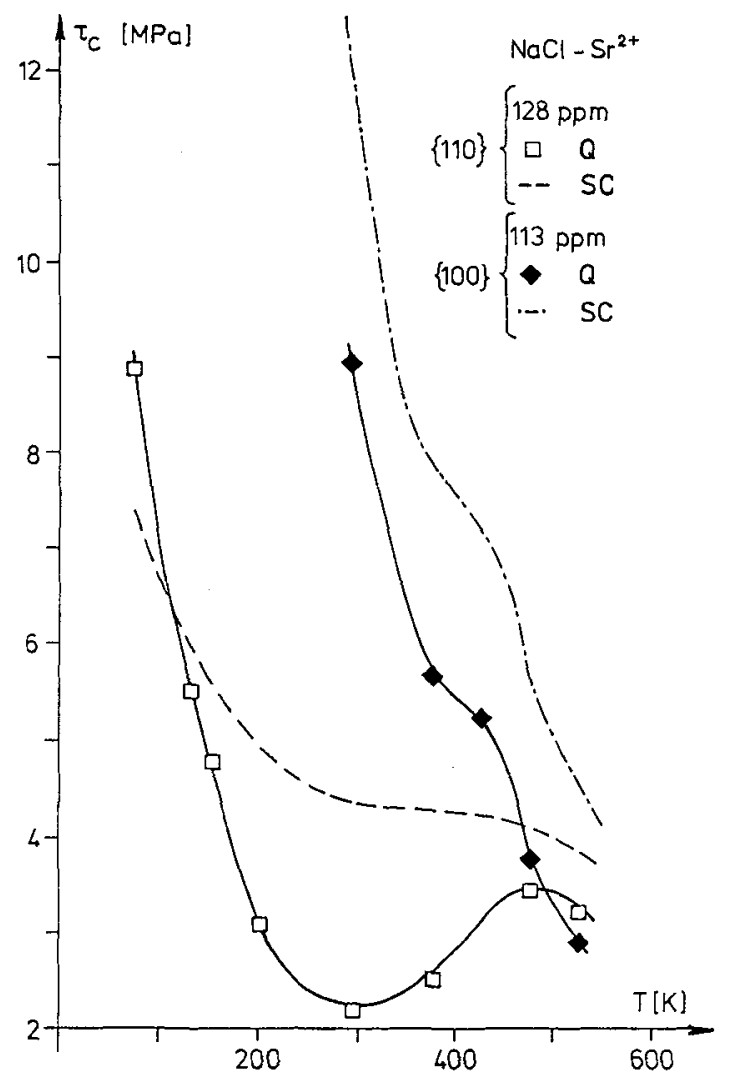

Fig.13.- Temperature dependence of the CRSS of NaCl-Sr ${ }^{2+}$ after different cooling treatments.

Regime IV. - Here the CRSS decreases towards a temperature independent limit. This decrease sets in at $T_{f} \approx 500 \mathrm{~K}$ for the alkali halides and at $\mathrm{T}_{\mathrm{f}} \gtrsim 250 \mathrm{~K}$ for $\mathrm{AgCl}$, reflecting a difference in the melting temperatures of these materials (AH: $T_{m}=(1074-954 \mathrm{~K}), A g C l: T_{m}=728 \mathrm{~K}$ ). An early high temperature drop shortens regime III, to be seen for $\{100\}$ and $\{110\}$ slip in figures $9 a$ and $b$, respectively.

4. Analysis and discussion of the results. - 4.1 Peierls mechenanis (regime_I).- The strong temperature dependence of the CRSS as well as the small activation volume suggest the Peierls mechanism as the rate controlling process in regime $I$. This has already been confirmed for $\{110\}$ and $\{100\}$ slip $/ 1,2,11 /$ by a detailed analysis of the low temperature results. A summary including some results given in section 3.2 .2 is presented in table II. 
Table II.- Experimental Peierls stresses, sum of the polarizabilities of the matrix ions $(\Sigma \alpha)$, static dielectric constant $\left(\varepsilon_{0}\right)$ and Cauchy relation $\left(c_{12} / c_{44}\right)$.

\begin{tabular}{|c|c|c|c|c|c|c|c|}
\hline & & $\mathrm{L}, \mathrm{iF}$ & $\mathrm{NaCl}$ & $\mathrm{KCl}$ & $\mathrm{KBr}$ & KJ & $\mathrm{AgCl}$ \\
\hline \multirow{2}{*}{$\tau_{p}[\mathrm{MPa}]$} & $\{100\}$ & $(\sim 320) *)$ & 140 & 80 & 70 & 50 & $\sim 35$ \\
\hline & $\{110\}$ & 20 & 11 & 35 & 35 & 28 & \\
\hline \multirow{2}{*}{${ }^{10^{3} \tau} \tau^{\{h k l\}} / \mu^{\{h k l\}}$} & $\{100\}$ & $(\sim 5)$ & 10 & 12 & 14 & 12 & $\sim 5$ \\
\hline & $\{110\}$ & 0.5 & 0.5 & 1.6 & 1.9 & 1.8 & \\
\hline \multicolumn{2}{|l|}{$\Sigma \alpha\left[10^{-30} \mathrm{~m}^{3}\right]$} & 0.90 & 3.21 & 4.13 & 5.25 & 7.28 & 4.97 \\
\hline \multicolumn{2}{|l|}{$\varepsilon_{0}$} & 8.5 & 5.45 & 4.49 & 4.52 & 4.68 & 9.55 \\
\hline \multicolumn{2}{|l|}{$C_{42} / c_{44}$} & 0.65 & 0.84 & 0.81 & 1.06 & 0.6 & 5.67 \\
\hline
\end{tabular}

*) Estimated from torsion experiments of Gilman $/ 14 /$.

From this table the following can be ascertained:

$-\tau_{p}\{100\}>\tau_{p}\{110\}, i . e$. the intrinsic resistance to glide on $\{100\}$ is stronger than on $\{110\}$ planes.

$-\left(\tau_{p} / \mu\right)^{\{100\}} \approx(10-14) \times 10^{-3},\left(\operatorname{LiF} \approx 5 \times 10^{-3}\right), \operatorname{AgCl} \approx 5 \times 10^{-3}$; $\left(\tau_{p} / \mu\right)^{\{110\}} \approx(0.5-1.9) \times 10^{-3}$ i.e. the reduced glide resistance is about one order of magnitude larger on $\{100\}$ than on $\{110\}$. The correlation of the Peierls stresses with the shear modulus $\mu$ is particularly poor for the alkali halides on $\{110\}$. - $\tau_{p}\{100\}$ decreases in the series from LiF to AgCl while $\tau_{p}\{110\}$ does

Since Buerger /15/ the intrinsic resistance to slip on $\{100\}$ planes has been correlated with the polarizability $(\Sigma \alpha)$ of the ions constituting the crystal. With increasing $\Sigma \alpha$ a decrease of $\tau_{p}\{100\}$ has been expected. The results on AgCl show however, that the polarizability which is directly connected with the static dielectric constant is not the only parameter determining $\{100\}$ slip. In comparison with the alkali halides the Cauchy relation is strongly violated in AgCl. As pointed out by Bücher /16/ this violation is essentially caused by a large threeoody contribution to the Van der Waals interactions. Furthermore the quadrupolar deformability of the silver ion seems to be relevant. Differences between AgCl and the alkali halides have also been attributed to covalent binding in the silver halides. However, neither calculations nor $x$-ray measurements of the electron density distribution give evidenc for such a contribution $/ 17 /$.

The Peierls stress of a crystal has been calculated with elastic and atomistic models. Only the atomistic calculations give reasonable values for $\tau_{p}$ and above all describe the plastic anisotropy correctly 
/11/. Calculated values are for NaCl: $\tau_{p}{ }^{\{100\}}=220 \mathrm{MPa} / 18 /, \tau_{p}{ }^{\{110\}}$ $=(14.1-21.5) \mathrm{MPa} / 3 /,(17.3 / 80.0) \mathrm{MPa} / 19 /$, for $\mathrm{KCl}: \tau_{\mathrm{p}}^{\{110\}}=(12.7-$ 32.4) $\mathrm{MPa} / 20 /, 30.4 \mathrm{MPa} / 21,22 /$. These values should be compared with table II. An extension of these calculations, especially to the silver halides with Van der Waals binding would be of great interest. Our investigation on the influence of doping on the CRSS in regime I shows that the observed increase seems to be additive to the low temperature steep increase of the CRSS for the "pure" crystals. These results differ from those obtained for alkali halide solid 123\% and bcc metallic alloys, both of which show alloy-softening in a certain temperature range. Further investigations of the doping effect on the Peierls mechanism in ionic crystals are planed.

4.2 Dis 10 ㅇation-solute loss measurements /24/ that for small concentrations and after a suitable thermal treatment the divalent impurities are paired with vacancies as required for charge compensation in the form of 'impurity-vacancy-dipoles' (IV-dipoles). For our standard cooling rate this condition seems to pertain in all crystals investigated except $\mathrm{NaCl}^{-\mathrm{Sr}^{2+}}$. Here quenching experiments show that analogous results can be obtained only by using a cooling rate which is about hundred times higher. The $\mathrm{Sr}^{2+}$ doped. ivaCl crystals pretreated under standard conditions will be discussed separately in section 4.3 .

4.2.1 Short-range interaction of dislocations with IV-dipoles (regime II). - The temperature as well as the concentration dependence of the CRSS suggest the onset of plastic deformation in regime II to be determined by a short-range interaction with IV-dipoles. For dilute alloys standard theories of solide solution hardening yield for this contribution /25/:

$$
\Delta \tau_{C}=\frac{f^{3 / 2}}{\left(2 E_{L}\right)^{1 / 2} b} c_{p}^{1 / 2}(1-\phi(T))
$$

$\left(c_{p}=\right.$ doping concentration per unit area of the slip plane, $c_{p} c^{2} ;=$ maximum interaction force solute-dislocation; $E_{L}=$ line tension; the temperature dependence (see eq. (4)) $\phi(T)=0$ for $T=0 \mathrm{~K}$ ). As will be shown in detail in section 4.2.4 from a comparison of the plateau stresses for $\{100\}$ and $\{110\}$ slip, even the CRSS of our purest crystals is determined by unknown background impurities. According to computer simulations /26/ of the movement of a dislocation over a statistical distribution of point obstacles of equal strength the CRSs contribution of the "pure" component is eliminated using a quadratic superposition 
law: $\Delta \tau_{c}=\left(\tau_{c}^{2}-\tau_{c u}^{2}\right)^{1 / 2},\left(\tau_{c u}=\right.$ CRSs of the "pure" crystals $) \cdot \tau_{c u}$ includes an athermal part $\tau_{\mu}$, which is assumed to be independent of doping. According to Frank /27/, doped crystals are filled during microstraining with dislocations until their interaction stress matches the CRSS determined by the doping. Figure 14 shows that the $\mathrm{c}^{1 / 2}$ dependence of $\Delta \tau$ is rather well established in regime II.

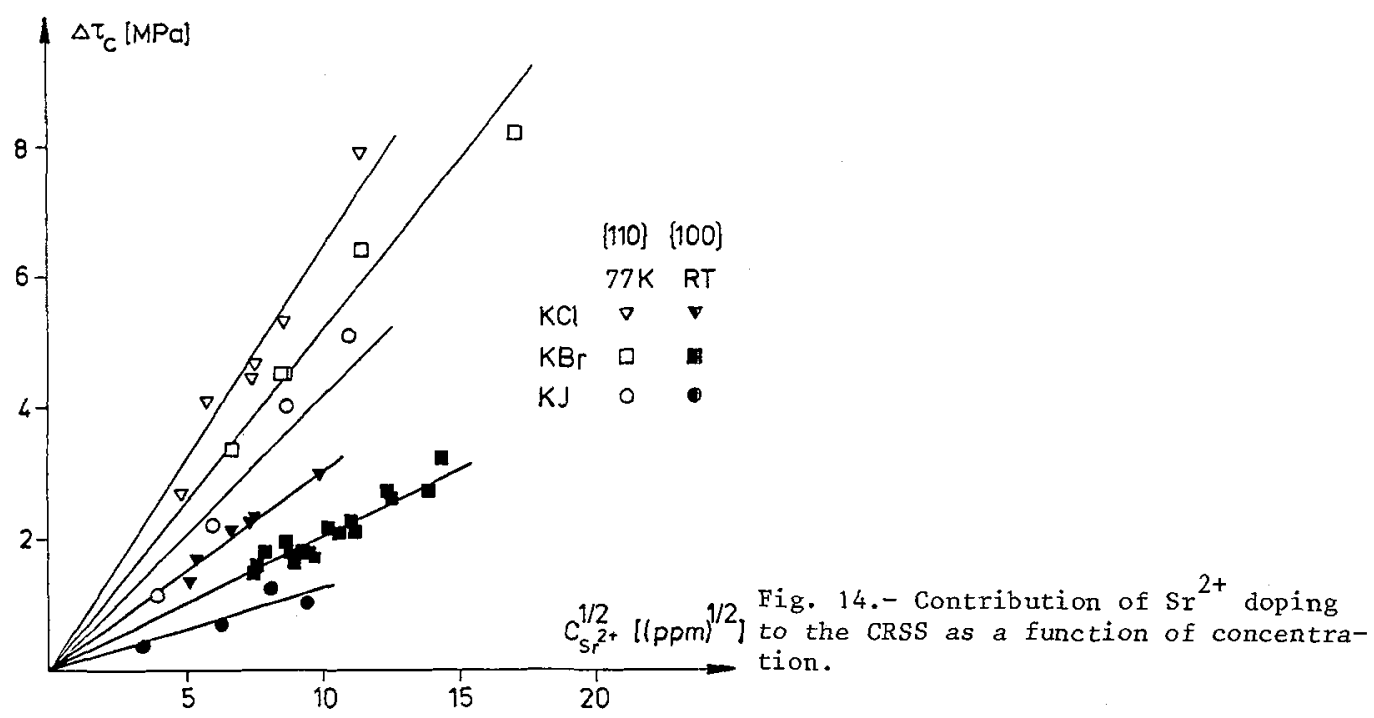

According to Ono /28/ the activation energy stress relation can be described for nearly any type of obstacle profile by

$$
\mathrm{U}\left(\tau_{\mathrm{C}}\right)=\mathrm{U}_{\mathrm{O}}\left(1-\left(\frac{\tau_{\mathrm{C}}}{\tau_{\mathrm{CO}}}\right) 1 / 2{ }^{3 / 2}\right.
$$

$\left(\tau_{\text {co }}=\right.$ CRSS at $\left.\mathrm{T}=\mathrm{OK}\right)$. Using an Arrhenius ansatz for the strain rate

$$
\dot{a}=a_{0} \exp \left(-u\left(\tau_{C}\right) / k T\right)
$$

the temperature dependence of the CRSS is given by

$$
\left(\frac{\tau_{C}}{\tau_{C O}}\right)^{1 / 2}=1-\left(-\frac{T}{T_{O}}\right)^{2 / 3}
$$

with

$$
T_{0}=U_{0} / k \ln \left(\dot{a}_{0} / \dot{a}\right)
$$


The experimental results, figure $15 \mathrm{a}$ and $\mathrm{b}$, are in agreement with this theoretical prediction. In figure $15 \mathrm{a}$ the "pure"component has not been eliminated. The $\tau_{c}{ }^{1 / 2}-T^{2 / 3}$ curves would however be changed only little by taking into account $\tau_{\mathrm{cu}}$. This diagram demonstrates once more the multi-staged decrease of $\tau_{C}(T)$. Values of the CRSS obtained by extrapolating the temperature dependence of regime II to $T=0 \mathrm{~K}$ are listed in table III. Because of the shortness of regime II these values are

Table III.- Specific hardening in regime II due to short-range interaction between dislocations and IV-dipoles. Quenched crystals are marked by a star.

\begin{tabular}{|c|c|c|c|c|c|c|c|c|}
\hline & & \multirow{2}{*}{$\frac{L i F}{M g^{2+}}$} & \multicolumn{2}{|c|}{$\mathrm{NaCl}$} & \multirow{2}{*}{$\frac{K C 1}{S r^{2+}}$} & \multirow{2}{*}{$\frac{K B r}{s r^{2+}}$} & \multirow{2}{*}{\begin{tabular}{|c|}
$K J$ \\
$S r^{2+}$ \\
\end{tabular}} & \multirow{2}{*}{$\frac{\mathrm{AgCl}}{\mathrm{Ca}^{2+}}$} \\
\hline & & & $\mathrm{Ca}^{2+}$ & $S r^{2+}$ & & & & \\
\hline \multirow{2}{*}{$\begin{array}{l}\Delta \tau_{C O} / C^{1 / 2} \\
{\left[\begin{array}{ll}10^{3} & \mathrm{MPa}\end{array}\right]}\end{array}$} & $\{100\}$ & & & $\geq 4.2 *$ & 3.3 & 3.2 & 2.2 & $\leq 0.9$ \\
\hline & $\{110\}$ & $\left.\left(68^{2}\right), 3\right)$ & $\begin{array}{l}1.6^{1)} \\
\left.1.6^{4}\right) \\
\end{array}$ & 1. $5^{\star}$ & 1.3 & 1.2 & 1,2 & \\
\hline \multirow{2}{*}{$\Delta \tau_{C O}^{\{h k 1\}} / C^{1 / 2} \mu^{\{h k 1\}}$} & $\{100\}$ & & & $\geqslant 0.32 *$ & 0.50 & 0.62 & 0.60 & $\leq 0.13$ \\
\hline & $\{110\}$ & $0.17^{*}$ & $\begin{array}{l}0.07 \\
0.07 *\end{array}$ & $0.07 *$ & 0.06 & 0.07 & 0.08 & \\
\hline
\end{tabular}

Ref.: 1) /7/,2) /13/,3) /29/, 4)/30/

connected with an error of about $20 \%$. The results of table III can be summarized as follows:

$-\left(\Delta \tau_{C O} / C^{1 / 2}\right)^{\{100\}}>\left(\Delta \tau_{C O} / C^{1 / 2}\right)^{\{110\}}$, i.e. the specific hardening is greater on $\{100\}$ than on $\{110\}$.

- $\left(\Delta \tau_{C O} / C^{1 / 2}\right)\{110\},\{100\}$ decrease in the series from LiF to AgCl. The decrease is stronger for $\{100\}$ than for $\{110\}$ slip.

$-\left(\Delta \tau_{\mathrm{CO}} / \mathrm{C}^{1 / 2} \mu\right)\{100\} \approx 0.5-0.62(\mathrm{AgCl} \lesssim 0.13),\left(\Delta \tau_{\mathrm{CO}} / \mathrm{C}^{1 / 2} \mu\right)$

$\approx 0.06-0.08$ (LiF $\simeq 0.17)$, i.e. the specific hardening is about one order of magnitude greater on $\{100\}$ than on $\{110\}$. The correlation of the specific hardening with the shear modulus alone is again poor. substituting in equation (1) $\mathrm{c}_{\mathrm{p}}=\frac{2 \sqrt{2}}{3} \quad \frac{\mathrm{c}}{\mathrm{b}^{2}} / 31 /$ and $\mathrm{E}_{\mathrm{L}} \simeq \frac{1}{2} \mu \mathrm{b}^{2}$ the maximum interaction force is given by

$$
\mathrm{f} \approx\left(\Delta \tau_{\mathrm{co}} / \mathrm{c}^{1 / 2} \mu\right)^{2 / 3} \mu \mathrm{b}^{2}
$$

Values estimated with the help of equation (6) from experiment are pre- 


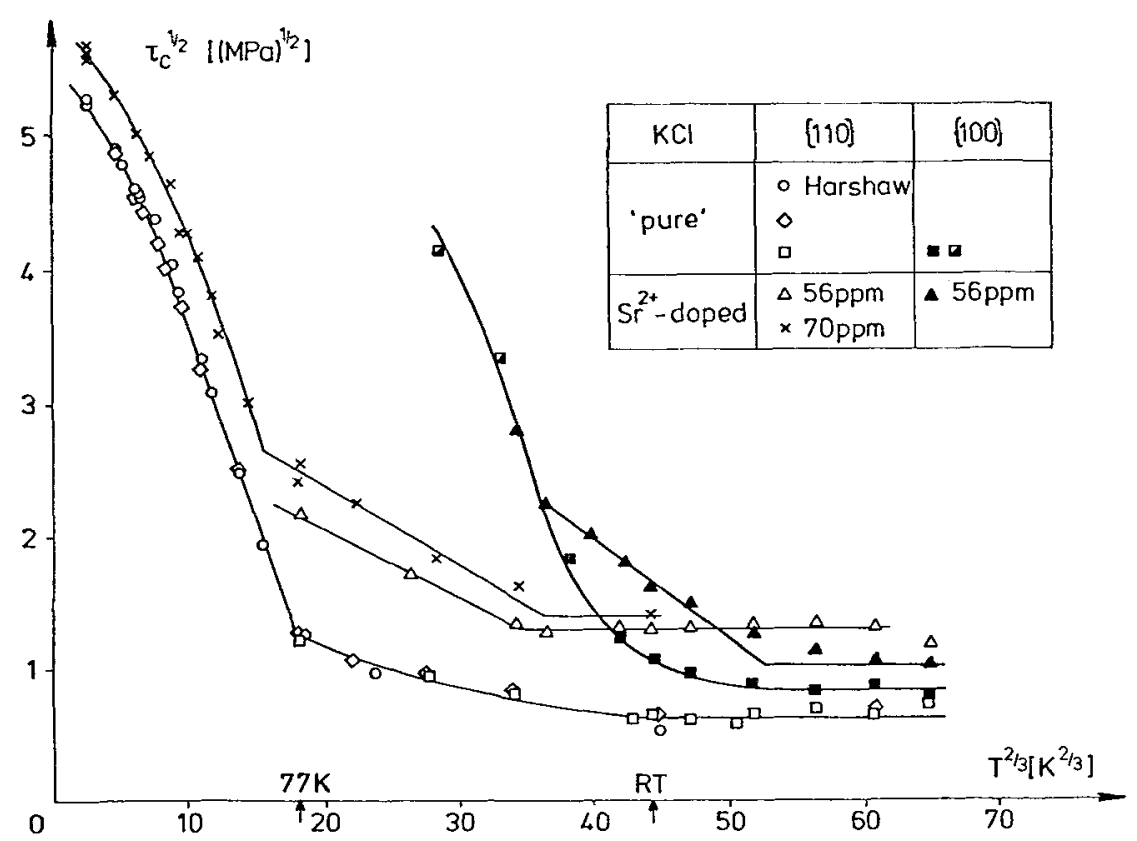

Eig. 15.- a) Temperature dependence of the CRSS of $\mathrm{KCl}$ in a $\tau_{C}{ }^{1 / 2}-\mathrm{T}^{2 / 3} \mathrm{plot}$, according to Ono.

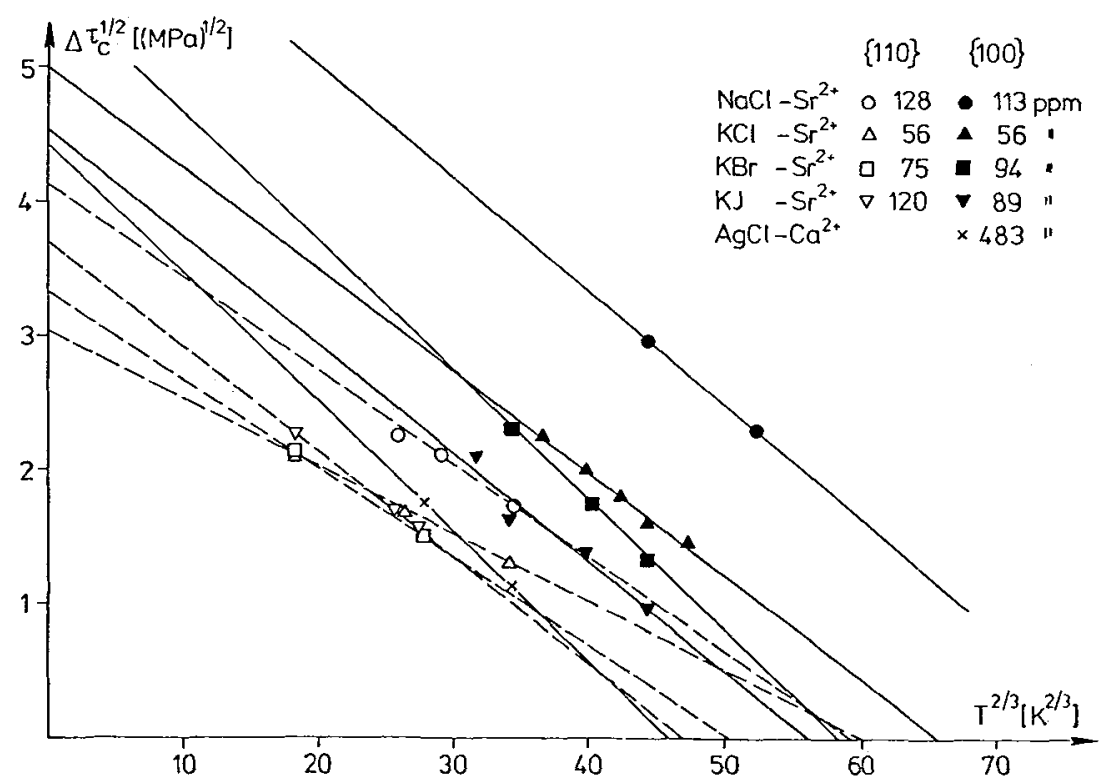

Fig. 15.- b) as (a) for the contribution $\Delta \tau_{\mathrm{c}}{ }^{1 / 2}$ of $\mathrm{Me}^{2+}$ doping. 


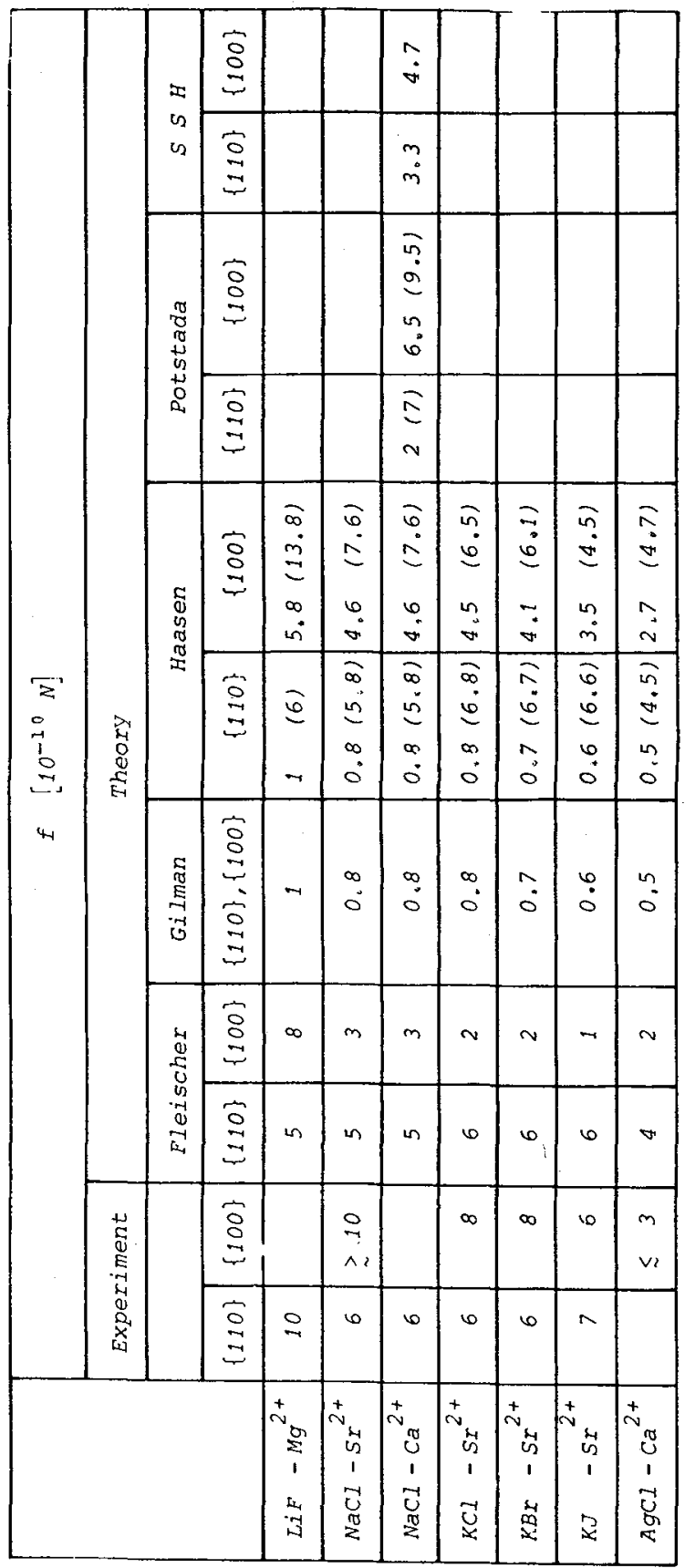


sented in table IV. In the following model calculations will be compared with these values regarding the order of magnitude as well as the correlation with ionicity.

A model which has attracted much attention in ionic crystals has been developed by Fleischer /32/ and is based on the elastic interaction between a dislocation and the tetragonal distortion around an IV-dipole. For the closest distance of the dipole to the slip plane $(b / 2)$ and for a defect volume of $2 \sqrt{2} b^{3} / 31 /$ the maximum interaction force is

$$
f \approx \mu b^{2} \Delta \varepsilon,
$$

$(\Delta \varepsilon=$ tetragonal distortion).

With $\Delta \varepsilon \approx 0.15$ (see section 4.2.2) values are obtained which are of the right order of magnitude, but except for LiF the anisotropy comes out wrong $f^{\{100\} / f}\{110\} \approx \mu\{100\} / \mu\{110\}<1$. This result is contrary to the experimental observations.

Gilman /33/ has proposed a short-range interaction which is based on the increase $\Delta \mathrm{U}$ of the electrostatic energy during shearing of a dipole. $\mathrm{f}$ is approximately given by

$$
f \approx \frac{\Delta U}{b}=0.3 \frac{e^{2}}{\varepsilon_{0} b^{2}},
$$

(e = electron charge).

An extension of this model by Mitchell and Heuer /31/, considering the displacement field of the dislocation yields values, which are only $30 \%$ higher. Gilman's model gives the right correlation of $f$ with the ionicity but it fails in describing the order of magnitude and does not take into account the plastic anisotropy.

Haasen /34/ ascribed the extrinsic plastic anisotropy to the electrostatic interaction of edge dislocations with IV-dipoles. This interaction is expected to be stronger for a $\{100\}\langle 110\rangle$ edge dislocation because its extra half plane ends with equally charged rows of ions, while for a $\{110\}<110>$ edge dislocation these rows consist of ions of alternating charge. Haasen calculates the maximum interaction energy in two steps. First the extra half plane is neutralized by ions of opposite charge and the interaction of these ions with the foreign ion is calculated. Secondly changes of this interaction are estimated when the extra half plane is actually removed and the surrounding lattice is allowed to relax to a dislocation configuration. $f$ is approximately derived as

$$
f \approx K-\frac{e^{2}}{\varepsilon_{0} b^{2}}
$$


with

$$
\begin{aligned}
& \mathrm{K}^{\{110\}}=0.3 \\
& \mathrm{~K}^{\{100\}}=1.7
\end{aligned}
$$

Haasen's model neglects the tetragonal distortion of the lattice around the dipole which arises from the attractive electrostatic interaction between divalent ion and vacancy. Taking this into account according to the elastic model of Fleischer, the experimental situation can be explained, i.e. the plastic anisotropy disappears with decreasing ionicity. However, the theory cannot account for the strong difference between $\mathrm{KJ}$ and $\mathrm{AgCl}$.

An advanced calculation of the electrostatic interaction energy has been given biy Potstada /35/. Using an atomistic model established by Granzer et al. /3/ he calculates a more realistic core configuration and besides the coulomb interaction he takes into account repulsion and Van der Waals terms as well as polarisation effects around charged point defects. Potstada's calculations are restricted to the maximun interaction energy of isolated $\mathrm{Ca}^{2+}$ ions and vacancies with edge dislocations in NaCl. Therefore in the case of dipoles the tetragonal distortion has not been considered. The maximum interaction force estimated agrees quite well with experiment, however.

In previous work of Skrotzki, Steinbrech and Haasen (SSH) /7/ an effective maximum interaction force has been estimated by superposition of the interactions of the two dipole orientations ( 1 and 2 ) assumed to be essential:

$$
f_{\text {eff }}=\left(\frac{1 f_{1}^{2}+f_{2}^{2}}{\sqrt{2}\left(f_{1}+f_{2}\right)^{1 / 2}}\right)^{2 / 3}
$$

$f_{i}$ consist of the electrostatic interaction calculated by Potstada and an elastic interaction. The agreement with the experimental results is better than a factor two.

For a more accurate analysis complete force distance profiles have to be calculated atomistically. Furthermore it seems to be important to consider different dipole orientations and to superpose their interactions according to a law given by Friedrichs and Haasen /36/. To explain the difference between alkali and silver halides the manybody contribution to the van derwals interaction should be taken into account.

4.2.2 Snoek-type interaction (regime III).- The linear concentration dependence as vell as the temperature insensitivity of the CRSs are 
indicative for a dislocation induced snoek effect /37,38/. Table V shows that the contribution to the CRSS due to snoek-type interaction is smaller for $\{100\}$ slip than for $\{110\}$. However, $\Delta \tau / c \mu$ is nearly constanc for both planes. This means that the snoek effect is mainly due Table V.- Specific hardening in regime III due to Snoek-type interactions. Quenched crystals are marked by a star.

\begin{tabular}{|c|c|c|c|c|c|c|c|c|}
\hline & \multirow{2}{*}{$\frac{L i F}{M g^{2+}}$} & \multicolumn{2}{|c|}{$\mathrm{NaCl}$} & \multirow{2}{*}{$\frac{K C 1}{s x^{2+}}$} & \multirow{2}{*}{$\frac{K B r}{S r^{2+}}$} & \multirow{2}{*}{$\frac{K I}{s r^{2+}}$} & \multirow{2}{*}{$\frac{A g C 1}{C a^{2+}}$} \\
\hline & & & $\mathrm{Ca}^{2+}$ & $s r^{2+}$ & & & & \\
\hline \multirow[b]{2}{*}{$\begin{array}{l}\Delta \mathrm{T}_{C^{\prime}} / \mathrm{C} \\
{\left[\begin{array}{ll}10^{4} & \mathrm{MPa}\end{array}\right]}\end{array}$} & $\{100\}$ & & & & 0.7 & 0.6 & 0.3 & \\
\hline & $\{110\}$ & $2.8^{*}$ & $\begin{array}{l}1.9^{1)} \\
\left.2.1^{* 3}\right)\end{array}$ & $1.1^{*}$ & $\begin{array}{l}2.0 \\
1.8 *\end{array}$ & $\begin{array}{l}1.5 \\
1.5 *\end{array}$ & 1.0 & $\geq 0.4$ \\
\hline \multirow{2}{*}{$\Delta \tau_{C}^{\{h k 1\}} / C \mu^{\{h k 1\}}$} & $\{100\}$ & & & & 1.2 & 1.2 & 0.8 & \\
\hline & $\{110\}$ & $0.8^{*}$ & $\begin{array}{l}1.1 \\
1.2^{*}\end{array}$ & $0.5 *$ & 1.2 & 1.0 & 0.9 & $\gtrsim 0.4$ \\
\hline
\end{tabular}

Ref.: $\left.\left.\left.{ }^{1}\right) / 7 /, 2\right) / 13 /, 3\right) / 39 /$.

to an elastic interaction. The short-range electrostatic interaction is of no importance in decreasing the free enthalpy of the dipoles surrounding a dislocation ("Snoek atmosphere").

The elastic contribution of the snoek effect to the CRSS has been estimated by Frank /38/, as

$$
\Delta \tau=\alpha \mu \Delta \varepsilon C_{D} \quad, \quad \text { if } \quad \nu_{r}{ }{ }_{0} / v \ll 1
$$

The time $r_{0} / v$, required by a dislocation of the velocity $v$ to go through the radius $r_{o}$ of the snoek atmosphere should be small compared with the time of reorientation of the dipole $1 / \nu_{r}\left(c_{D}=\right.$ concentration of IV-dipoles). With $\alpha \approx 7$ for the stronger interacting edge component reasonabla values for $\Delta \varepsilon$ between 0.1 and 0.2 are obtained. Theoretical calculations of $\Delta \varepsilon$ are not known, however.

4.2.3. Dissociation and drag of IV-dipoles (regime IV).- According to the analysis of sections 4.2 .1 and 4.2 .2 two mechanisms are possible for the high temperature drop of the CRSS:

- dissociation of the IV-dipoles,

- dragging of the snoek atomsphere.

The dissociation of dipoles with increasing temperature is quantitatively described by the mass-action law 


$$
\frac{\left(\mathrm{c}-\mathrm{c}_{\mathrm{D}}\right)^{2}}{\mathrm{C}_{\mathrm{D}}}=\frac{1}{12} \exp \left(-\Delta \mathrm{g}_{\mathrm{b}} / \mathrm{k} \mathrm{T}\right)
$$

$\left(\Delta \mathrm{g}_{\mathrm{b}}=\right.$ change of the free entalpy during dissociation). According to equation (11) the snoek effect decreases by $20 \%$, if $C_{D}=0.8 \mathrm{c}$. This concentration is reached in alkali halides with $c \approx 5 \times 10^{-5}$ and $\Delta g_{b}$ A $0.5 \mathrm{eV} / 40 /$ at $\mathrm{T}_{\mathrm{f}} / \mathrm{T}_{\mathrm{m}}$ क $0.5 \mathrm{i}$.e. close to the observed values. The dissociation of dipoles cannot however explain the smaller $\mathrm{T}_{f}$ of AgCl, because the binding energy of divalent ions to vacancies in this material is about $0.5 \mathrm{eV} / 41 /$, too.

At high temperatures or small strain rates the snoek atmospheres are able to follow the moving dislocations. According to Frank /38/ in this case equation ( $11^{-}$) must be replaced by

$$
\Delta \tau_{C}=\alpha \mu \Delta \varepsilon C_{D} f(h)
$$

with

$$
f(h)=f\left(\nu_{r}{ }^{\prime} / v\right)
$$

For $h=1, f(h)$ is about 0.8 . The condition $h=1$ and

$$
\begin{aligned}
& v_{r}=v_{\text {ro }} \exp \left(-\Delta g_{r} / k T\right) \\
& r_{0}=\beta \Delta \varepsilon b T_{\mathrm{m}} / T \\
& v=\dot{a} / \mathrm{Nb}
\end{aligned}
$$

$\left(\Delta \mathrm{g}_{\mathrm{r}}=\right.$ free enthalpy of reorientation, $\mathrm{N}=$ mobile dislocation density, $v_{\text {ro }} \approx 5 \times 10^{13} \mathrm{~s}^{-1}, \beta \approx 50$ ) yields

$$
T_{f}=\frac{\Delta g_{r}}{h} / \ln \frac{\nu_{r o} \beta b^{2} \Delta E N T_{m}}{\dot{a} T_{f}}
$$

with $\Delta \varepsilon \approx 0.15, \dot{\mathrm{a}} \approx 10^{-4} \mathrm{~s}^{-1}$ and $\Delta \mathrm{g}_{\mathrm{r}} \approx 0.7 \mathrm{eV} / 40 /$ in alkali halides the mobile dislocation density is about $10^{5} / \mathrm{cm}^{2}$ at $T_{f} / T_{m} \approx 0.5$. Because this value appears reasonable it is assumed that in alkali halides dragging of IV-dipoles contributes to the high temperature drop in CRss. 4.2.4 Obstacles in "pure"crystals. - The analysis of the hardening due to doping depends on the way of elimination of the "pure"component from the measured CRSS. Therefore it is important to identify the obstacles determining the CRSS of the pure crystals. In the following this will be attempted with the aid of the measured plastic anisotropy. 
Table VI.- Plateau stresses of the "pure" crystals.

\begin{tabular}{|l|c|c|c|c|c|c|}
\hline \multicolumn{2}{|c|}{} & $N a C I$ & $K C I$ & $K B I$ & $K J$ & $A g C 1$ \\
\hline \multirow{2}{*}{$\tau_{C}[\mathrm{MPa}]$} & $\{100\}$ & 2.3 & 0.7 & 0.6 & 0.4 & 0.5 \\
\cline { 2 - 8 } & $\{110\}$ & 0.65 & 0.45 & 0.5 & 0.45 & 0.5 \\
\hline \multirow{2}{*}{$10^{4} \tau_{C}^{\{h k I\} / \mu}\{h k I\}$} & $\{100\}$ & 2.0 & 1.2 & 1.2 & 1.1 & 0.8 \\
\cline { 2 - 7 } & $\{110\}$ & 0.4 & 0.3 & 0.3 & 0.4 & 0.4 \\
\hline
\end{tabular}

Table VI presents the plateau stresses of the "pure" crystals. Striking are the following results:

1) $\tau_{c}\{100\} \geq \tau_{c}\{110\}$, i.e. in the plateau range slip on $\{100\}$ is more difficult than on $\{110\}$.

2) $\tau_{C}\{100\}$ becomes smallex with decreasing ionicity, while $\tau_{C}\{110\}$ is nearly constant.

3) $\left(\tau_{c} / \mu\right)\{100\} \approx(0.3-2) \times 10^{-4}$, $\left(\tau_{c} / \mu\right)^{\{110\}} \approx 0.35 \quad \times 10^{-4}$,

i.e. $\tau_{c} / \mu$ is about 2 - 5 times larger for cube plane slip. From 3) it is concluded that the CRSS of the "pure" crystals cannot be determined just by dislocation-dislocation interactions. Considering the intersection of dislocations /42/ or the passing of parallel dislocations the CRSS should be proportional to the shear modulus: $\tau_{c} \sim \mu b \sqrt{\rho}(\rho=$ dislocation density $)$. The same holds for dipoles of unknown impurities or "eigen"-dipoles of interstitial ions /43/, because in this case the plateau stress should be determined by a snoekeffect.

Points 1) and 2) suggest the CRSS of the purest investigated crystals to be determined by impurity aggregates. Such aggregates of IVdipoles or anion complexes -e.g. $\mathrm{OH}^{-}, \mathrm{CO}_{3}{ }^{2-}, \mathrm{SO}_{4}{ }^{2-}, \mathrm{O}_{2}{ }^{2-}-$ are already present in the starting material or may come from the crucible or the atmosphere during crystal growth. Impurity aggregates give rise to short-range electrostatic interaction which should be more important for $\{100\}$ than for $\{110\}$ slip. Assuming that all crystals contain about the same concentration of these aggregates the correlation of the plateau stresses with ionicity can be understood. Furthermore aggregates are more difficult to surmount by thermal activation than IV-dipoles yielding only a weakly temperature dependent contribution to the CRSS. 
for precipitation of $\mathrm{Sr}^{2+}$ ions is stronger in $\mathrm{NaCl}$ than in the other investigated crystals as suggested from the dependence of the CRSS on the cooling rate. From the decrease of the dipole concentration during annealing of doped and quenched alkali halides Dryden et al. /24/ conclude that dimers, trimers and higher aggregates of IV-dipoles are formed. In crystals containing such complexes the CRSS is determined by the forces required to cut or pass these aggregates. For a quantitative treatment of this precipitation hardening the knowledge of the particle concentration as well as their size distribution is needed. These informations are not available at present.

From the investigations of Dryden et al. Frank /44/ concludes that after a certain thermal pretreatment of the crystals the IV-dipoles exist in complexes of uniform size consisting of $\mathrm{n}$ dipoles. Assuming equilibrium between $\mathrm{c}_{\mathrm{n}}$ and the concentration of non-agglomerated dipoles $c_{D}$ he obtaines for high $\mathrm{Me}^{2+}$ concentrations and $\mathrm{n} 23$

$$
\Delta \tau_{C} \sim c^{1 / 2}
$$

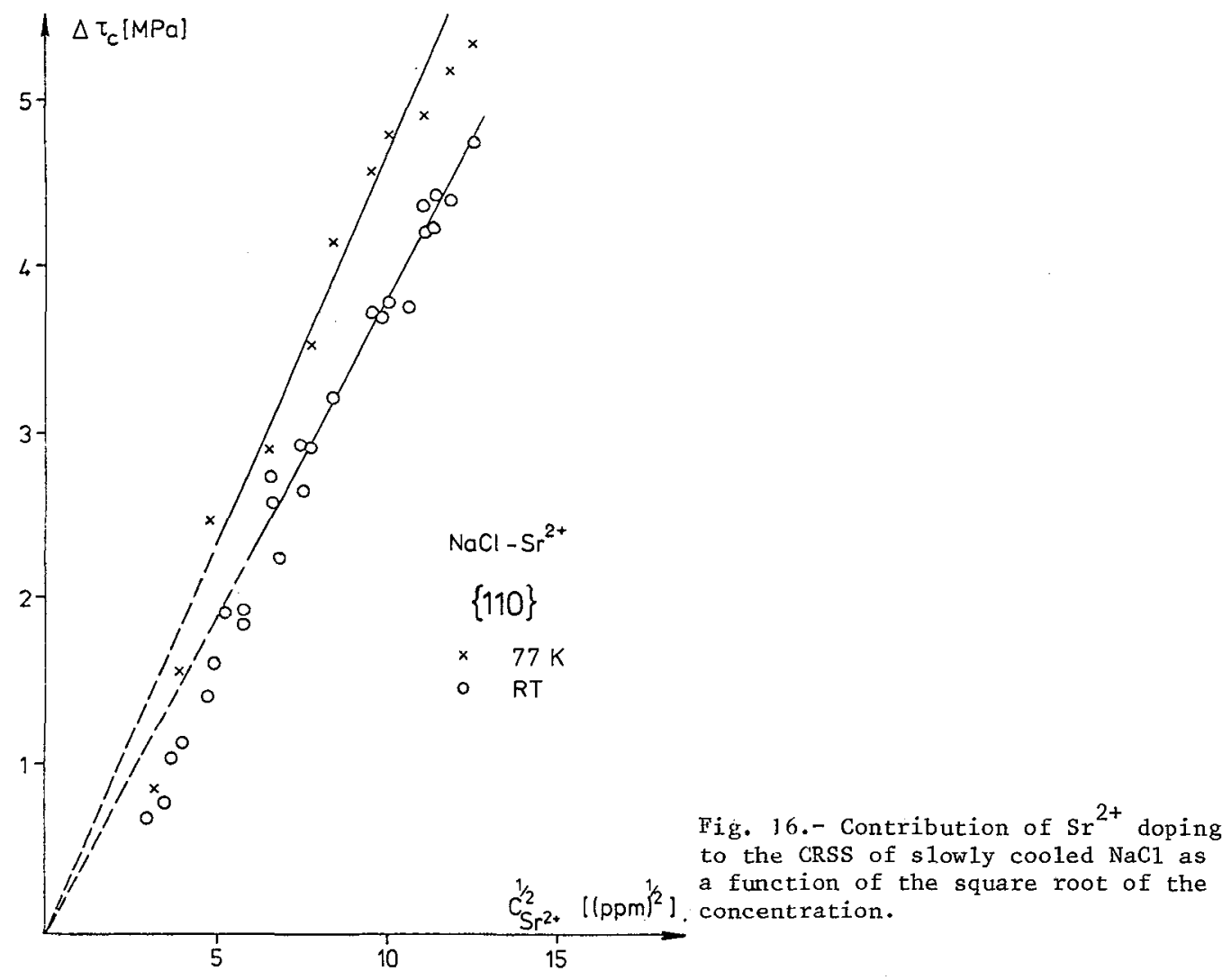


In figure $16 \Delta \tau_{C}$ for $\mathrm{NaCl}-\mathrm{Sr}^{2+}$ is plotted versus the square root of the total $\mathrm{Sr}^{2+}$ content. Assuming that in $\mathrm{NaCl}$ the complexes are the domineering obstacles for dislocation motion the "pure" component has been substracted linearly according to Foreman and Makin /26/. Figure 16 shows that equation (19) holds for concentrations $\mathrm{c}_{\mathrm{Sr}} 2+\succsim 30 \mathrm{ppm}$. Furthermore $\Delta \tau_{C}$ is only weakly temperature dependent. This means, that aggregates exist of at least three dipoles and that these complexes are difficult to surmourt by thermal activation.

The influence of dipole aggregates on $\{100\}$ slip cannot be separated clearly in $\mathrm{NaCl}$ because there exists no distinct range between regimes I and IV. Quenched crystals show a strong increase of the CRSS above RT. This increase is probably due to the formation of dipole aggregates.

For the solubility of impurity atorn in metals the size misfit is an important parameter. In ionic crystals this misfit is given by

$$
\delta=\frac{r_{M e^{2+-r}} \text { cation }}{r_{\text {cation }}}
$$

$(r=$ ionic radius), where

$$
\begin{aligned}
& \delta=2 \% \text { between } \mathrm{Na}^{+} \text {and } \mathrm{Ca}^{2+}, \\
& \delta=14 \% \text { between } \mathrm{Na}^{+} \text {and } \mathrm{Sr}^{2+},
\end{aligned}
$$

and $\delta=16 \%$ between $\mathrm{K}^{+}$and $\mathrm{Sr}^{2+} / 45 /$.

These values show that the tendency for a gregation is correctly described within the same material ( $\mathrm{NaCl}$ ) but not in comparison with $\mathrm{KCl}$. Obviously electrostatic interactions play an important role here, too. Acknowledgements.- The authors enjoyed the cooperation with Prof. T. Suzuki (Institute of Industrial Science, University of Tokyo) during his stay in Göttingen. Thanks are due to Dr. W. ABmus (Universität Frankfurt) for growing AgCl crystals and to $V$. Hollmann for laboratory work. This work has been supported by DFG through SFB 126/Kristal1-Labor. 


\section{References}

/1/ Suzuki, T., Kim, H., J. Phys. Soc. Jpn. 39 (1975) 1566

/2/ Suzuki, T., Him, H., J. Phys. Soc. Jpn. 40 (1976) 1703

/3/ Granzer, F., wagner, G., Eisenblätter, J., Phys. Status Solidi 30 (1968) 587

/4/ Frank, w., Phys. Status Solidi 29 (1968) 391

/5/ Suszynska, i1., Bull. Acad. Pol. Sci. Ser. Sci. Tech. 25 (1977) 315

/6/ Grau, P.,Fröhlich, F., Phys. Status Solidi A 55 (1979) 479

/7/ Skrotzki, W., Steinbrech, R., Haasen, P., Mater. Sci. Eng. $\underline{32}$ (1978) 551

18/ Aßmus, W., Pappert, G., Granzer, F., J. Cryst. Growth. $41 \quad(1977) \quad 172$

19/ Skrotzki, W., Ph. D. Thesis, Göttingen (1980)

/10/ Bhagavan Raju, I.V.K., Strunk, H., Phys. Status Solidi A $\underline{53}$ (1979) 211

/1l/ Suzuki, T., Skrotzki, W., Haasen, P., Phys. Status Solidi A to be published

/12/ Franzbecker, W., Diploma Thesis, Göttingen (1969)

/13/ Johnston, W.G., J. Appl. Phys. 33 (1962) 2050

/14/ Gilman, J.J., Acta Metall. 7 (1959) 608

/15/ Buerger, M.J., Am. Mineral.15 (1930) 226, 16 (1931) 237

/16/ Bücher, M., Ph. D. Thesis, Frankfurt (1977)

$117 /$ Granzer, F., "DGPh Intern", Sonderausgabe zum Münchner Symposium, (1979), private communication

/18/ Huntington, H.B., Dickey, J.E., Thomson, R., Phys. Rev. 100 (1955) 1117

/19/ Puls, M.P., So, C.B., Phys. Status Solidi B 98 (1980) 87

/20/ Hoagland, R.G., Hirth, J.P., Gehlen, P.C., Philos. Mag. $34(1976) 413$

/21/Woo, C.H., Puls, M.P., J. Phys. C 9 (1976) 127

/22/ Puls, M.P., AECL report 6929 (1980)

/23/ Kataoka, T., Uematsu, T., Yamada, T., Jpn. J. Appl. Phys. 17 (1978) 217

/24/ Dryden, J.S., Morimoto, S., Cook, J.S., Philos. Mag. 12 (1965) 379

/25/ Labusch, R., Acta Metall. 20 (1972) 917

/26/ Foreman, A.J.E., Makin, M.J., Philos. Mag. 14 (1966) 911

/27/ Frank, W., Mater. Sci. Eng. 6 (1970) 132

/28/ Ono, K., J. Appl. Phys. 39 (I968) 1803 
/29/Guiu, F., Langdon, T.G., Philos. Mag. 30 (1974) 145

/30/ Suzuki, T., unpublished

/31/ Mitchell, T.E., Heuer, A.H., Mater, Sci. Eng. 28 (1977) 81

/32/ Fleischer, R., Acta Metall, 10 (1962) 835

/33/ Gilman, J.J., J. Appl. Phys. 45 (1974) 508

134/ Haasen, P., in: Dislocations et Processes de Transport, J. Physique Colloq. 9 (1973) C9- 205

/35/ Potstada, H.H., Diploma thesis, Frankfurt (1975)

/36/ Friedrichs, J., Haasen, P., Philos. Mag. 31 (1975) 863

/37/ Schoeck, G., Seeger, A., Acta Metall. 7 (1959) 469

/38/ Frank, W., Z. Naturforsch. 22a (1967) 377

/39/ Hesse, J., Phys. Status Solidi A 21, (1967) 495

/40/ Barr, L.W., Lidiard, A.B., in Physical Chemistry, Vol. X

(Acad. Press N.Y./London) 1970

/41/ Abbink, H.C., Martin, D.S., J. Phys. Chem. Solids 27 (1966) 205

/42/ Frank, W., Mater. Sci. Eng. 6 (1970) 121

/43/ Frank, W., Phys. Status Solidi $\underline{29}$ (1968) 391

/44/ Frank, W., Phys. Status. Solidi 29 (1968) 767

/45/ Shannon, R.D., Prewitt, C.T., Acta Crystallogr. Sect. B 25 (1969) 925 